Vol. 20 (2016), pp. 292-320

ISSNe: 2530-6324 || ISSN: 1138-039X

DOI: https://doi.org/10.17979/afdudc.2016.20.0.1926

\title{
LA CHARÍA Y EL FIQH: SU SIGNIFICADO COMO CORPUS LEGAL
}

\author{
HANA JALLOUL MURO \\ Doctora en Derecho Internacional Público y Relaciones Internaciones. \\ Investigadora de la Universidad Complutense de Madrid
}

Fecha de recepción: 30.6 .2016

Fecha de aceptación: 28.7.2016

\begin{abstract}
Resumen: Se puede calificar la charía y el fiqh como las características más genuinas del islam, es más, muchos los consideran la espina dorsal de la religión musulmana; ambas aluden al derecho producido en la historia del Islam desde sus orígenes hasta la actualidad, en su totalidad (incluyendo jurisprudencia y doctrina). Este último hace referencia al conjunto de preceptos divinos y a los análisis de expertos juristas basados en el texto original, el Corán y en la Sunna, para la derivación de normas provenientes de las mismas fuentes, a través de la metodología legal de la jurisprudencia islámica. La charía no sólo abarca normativa legal sino que es un código ético y moral que muestra la voluntad divina, y el deseo de la consecución de la misma, para ser puesta en práctica por la comunidad de musulmanes. Comprender la diferencia entre ambos conceptos, charía y fiqh, ayuda a fomentar el dinamismo de la ley para su adaptación a contextos sociales determinados, y a desestimar afirmaciones hechas en nombre de la charía.
\end{abstract}

Palabras clave: charía-fiqh; ley islámica; jurisprudencia; doctrina; metodología legal e interpretación.

Abstract: Sharia and fiqh can be described as the most genuine characteristics of Islam, in fact, many consider them the backbone of the Muslim religion; both refer to the law produced in the history of Islam from its origins to the present time (including jurisprudence and legal doctrine). It refers to the set of divine precepts and to the analysis of legal experts based on the original text, the Koran and the Sunna, for the derivation of rules from the same sources through the legal methodology of Islamic jurisprudence. Sharia law covers not only legal rules; it is an ethical and moral code that presents the divine will in order to be fulfilled by the community of Muslims. 
Understanding the difference between the two concepts, sharia and figh, help to promote the dynamism of the law to adapt to specific social contexts, and to dismiss claims made on behalf of the sharia.

Key words: sharia; fiqh; islamic law; jurisprudence; legal doctrine; legal methodology and interpretation.

SUMARIO: I. INTRODUCCIÓN. II. LA CHARÍA. 1. El Corán. 2. La Sunna. III. EL FIQH. IV. CONCLUSIÓN

\section{INTRODUCCIÓN}

La charía es una parte consustancial de la estructura deontológica que comporta el islam ${ }^{1}$. El islam es una religión o $\operatorname{din}^{2}$ que engloba preceptos legales, morales, políticos, económicos y sociales.

A la hora de mencionar la charía necesitamos entender qué es, cual es su objetivo principal y cuál es su estatus como corpus legal en las sociedades actuales. Para ello se necesita la descripción terminológica de dos vocablos fundamentales: el de charía y el de fiqh, ambos vocablos árabes. Éstos últimos se conocen o traducen de distintas maneras tanto en castellano como en francés o inglés, así, son descritos como

\footnotetext{
${ }^{1}$ Nos referimos a Islam en mayúscula para designar la civilización islámica e islam en minúscula para referirnos a la religión, si bien muchas veces la distinción se diluye en el contexto y se vuelve difícil de aprehender. Distinción que también existe entre Cristiandad y cristianismo. Del mismo modo, utilizaremos el término "mundo islámico" cuando hacemos referencia al conjunto de musulmanes, comprende aquellos países y comunidades que tienen como religión mayoritaria el Islam. SEGURA I MAS, A., Aproximación al mundo islámico. Editorial UOC. Barcelona. 2002. p.15. Del mismo modo nos hemos decantado por la transcripción en castellano del término charía y no sharía, como aparece en la obra de GÓMEZ GARCÍA, L., Diccionario de Islam e islamismo. Espasa Calpe, Madrid. 2009. p. 59; aunque se puede encontrar ambos términos en castellano indistintamente si bien no figura todavía en el diccionario de la RAE, a diferencia de otros como sunna.

${ }^{2}$ La palabra Din es traducida como religión, islam, fe verdadera en AL-KHUDRAWI, D., Dictionary of islamic terms, Qamus al-lafoz al-islamiya. Arabic-english, english-arabic. Al Yamana, Beirut 2010. p. 174. El Corán menciona en la sura de la Familia de Imrán que 'La práctica de adoración/fe verdadera ante Allah es el islam' (inna al din a'inda Allah hwa al Islam).En El Noble Corán y su traducción comentario en lengua española. (Traducción y comentario de A G. Melara Navio) Complejo del Rey Fahd para la edición del Noble Corán en Medina Al Munawara. Bajo la supervisión del Ministerio de Asuntos Islámicos, Hadices, Propagación y Orientación del Reino de Arabia Saudí. Año 1417 de la Hégira (1996). 3:19. p.83. Según el Oxford Dictionary of Islam, Din es el tipo de vida elegido por Dios para el beneficio temporal y eterno; el Din conlleva creencias, pensamiento, carácter, comportamiento y obras. Si estos aspectos se derivan de la guía de Dios, como enseñaron originariamente los profetas, entonces abarcarían el Islam. Pero si estos se obtienen de innovaciones humanas o son desviaciones de las enseñanzas proféticas entonces son consideradas generalmente como diferentes vías que los individuos o grupos han escogido para sí mismos. Por ello, el islam o la sumisión pacifica a Dios en la creencia, carácter, rituales e interacciones sociopolíticas y económicas, se denomina 'el camino de la verdad' (din al-haqq), la vía aceptada por Dios. La adoración sincera de Dios exclusivamente es el 'camino recto' establecido para la vida humana (al-din al-qayyim). En ESPOSITO, JL., Oxford dictionary of Islam. Oxford University Press, 2003, p. 68. Hamidullah comenta que el vocablo Diin aparece en la Constitución de Medina haciendo alusión a los términos religión y gobierno, en HAMIDULLAH,M., "The first written constitution of the world". 1941 en https://archive.org/details/THEFIRSTWRITTENCONSTITUTIONOFTHEWORLD p.30.
} 
"derecho islámico", "ley islámica", "jurisprudencia islámica", "islamic law", "Mohamedan law", "islamic jurisprudence", "jurisprudence islamique", etc.

De aquí se deriva la necesidad de una comprensión más adecuada de los términos expuestos para poder entender su marco de acción específicamente en el plano legal.

Por consiguiente, podríamos precisar que la charía es la fuente de la ley divina o sagrada, puesto que se compone de dos fuentes, la primera el Corán ${ }^{4}$, que fue revelado por Dios al Profeta Muhammad, además de la Sunna, es decir, los dichos y hechos del Profeta, lo que fue aprobado y desaprobado por él implícita y explícitamente. Por su parte, el fiqh se encarga del conocimiento de las reglas de la ley sagrada. El fiqh es el estudio de las fuentes sagradas para la identificación de las prescripciones religiosas, de las obligaciones que constituyen las leyes y deberes religiosos.

No se debe obviar que existen diferencias en la interpretación de la ley por parte de las comunidades religiosas musulmanas suní y chií, así como diferentes escuelas jurídicas y algunas variaciones en la metodología legal que ambas utilizan para derivar normativa legal.

Según la Enciclopedia Jurídica, el término “jurisprudencia” se describe como:

"Doctrina jurídica asentada mediante resoluciones judiciales reiteradas de los tribunales. Su función principal es la de completar e integrar el ordenamiento jurídico. A pesar de que formalmente la jurisprudencia no es una fuente del Derecho (CC, art. 1.1), desde un punto de vista práctico sí debe ser considerada como tal. En España sientan jurisprudencia las sentencias del Tribunal Supremo y del Tribunal Constitucional, este último exclusivamente en materia de garantías constitucionales, fia $\mathrm{CC}$, art. 1.6;:LEC,art.4/7.

Antiguamente, ciencia del derecho. En sentido más preciso y más moderno, solución sugerida por un conjunto de decisiones suficientemente concordantes, emitidas por las jurisdicciones acerca de una cuestión de Derecho".

La misma Enciclopedia explica que la "doctrina" es:

"Pensamiento de los autores. Por extensión, conjunto de los autores. Conjunto de tesis y opiniones de los tratadistas y estudiosos del Derecho que explican y fijan el sentido de las leyes o sugieren soluciones para cuestiones aún no legisladas. Tiene importancia como fuente inmediata del Derecho, ya

\footnotetext{
${ }^{3}$ También ha sido definida como Islamic religious law. GRIFFEL, F., "Introduction", pp.1-19 en AA.VV. (ed.: AMANAT, A. y GRIFFEL, F.) Shari'a: Islamic law in the contemporary context. Standford University Press. California, 2007. p. 1. LAROUI, A., (Trad: C. Ruiz Bravo) El Islam árabe y sus problemas, Ediciones de península. Edición 2001.Barcelona p.35.

${ }^{4}$ El término Corán se deriva de la palabra árabe con la misma raíz Qara’a (leer), ya que Corán se refiere a los versos que el Profeta Muhammad recibía de Dios y eran leídos por el arcángel Gabriel. Se suele identificar la palabra Corán con la de Mushaf dándoles el mismo sentido, pero éstas se diferencian en el hecho de que esta última se refiere a la forma escrita de la revelación.

5 Entradas "doctrina" y "jurisprudencia" de la Enciclopedia Jurídica, disponible en http://www.enciclopedia-juridica.biz14.com/d/doctrina/doctrina.htm
} 
que el prestigio y la autoridad de los destacados juristas influye en a menudo sobre la labor del legislador e incluso en la interpretación judicial de los textos vigentes".

Autores como Dupret ${ }^{6}$ señalan que:

"Se considera que el Corán y la Tradición del Profeta son los dos pilares de Ley islámica. Conviene señalar que el texto coránico, tal como fue fijado en los cincuenta años posteriores a la muerte de Muhammad, y el corpus de la Sunna (la tradición), tal como fue acumulándose durante más de dos siglos a partir de la Hégira, comienzo de la era musulmana, no están más que marginalmente relacionados con la prescripción y la proscripción, como lo recomendado y lo prohibido [...] las dos mayores fuentes de la charía, tanto en el curso de su constitución como tras haber sido fijadas, han dependido siempre de la lectura que proponían sus especialistas [...] la literatura sobre la ley islámica".

Entonces nos parece más adecuado denominar ley Islámica a la charía y doctrina islámica o doctrina legal al Fiqh ${ }^{7}$; hay que tener siempre en cuenta que el Corán y la Sunna contienen muchos relatos y exhortaciones que no son obligaciones. Las obligaciones deben ser extraídas por el fiqh. Otros autores como Hallaq ${ }^{8}$ también definen el fiqh como "doctrina legal" o legal doctrine.

La comprensión de ambos términos nos ayudará a dilucidar el rol de cada uno huyendo de las pretensiones holísticas y las amalgamas que han caracterizado a lo largo de la historia los análisis de la charía.

Dupret vuelve a afirmar que "el conocimiento de la Ley islámica, es decir, de su doctrina, es una de las principales disciplinas del Islam erudito". Y también que: "Por tanto, la Ley islámica esta codificada en parte". . De aquí inferimos que el autor aunque distingue claramente los términos, a veces entiende la doctrina como la evolución de la ley. Ya que una vez interpretada, la doctrina puede ser también ley, o sea, ley derivada

\footnotetext{
${ }^{6}$ DUPRET, B., (Trad: J. Miguel Marcén), La sharía. Orígenes, desarrollo y usos contemporáneos. Biblioteca del Islam Contemporáneo. Ediciones Bellaterra.. Barcelona. 2015.

${ }^{7}$ También está la definición de la Real Academia Española sobre el derecho que se entiende, entre otras definiciones, como "principios y normas expresivos de una idea de justicia y de orden que regulan las relaciones humanas en toda sociedad y cuya observancia puede ser impuesta de manera coactiva. Ciencia que estudia estos principios y preceptos" es este sentido se acercaría también al termino Fiqh. Diccionario de la lengua Española. Vigésimo segunda edición. Madid.2001. (ley, jurisprudencia y derecho) pp. 751, 1332 y 1371. Tomo I. Del mismo modo el término ““derecho islámico” es totalmente ajeno a la ley islámica, es de uso reciente y corresponde a la aprensión por la ciencia occidental de las disposiciones propiamente jurídicas de la charía", AA.VV. (ed: A. BORRAS y S. MERNISSI ), El Islam jurídico y Europa, derecho, religión y política. Icaria Editorial. Antrazyt. Barcelona, 1998. p. 70. Dupret comenta acerca del "derecho musulmán" que "La idea de transformar las reglas islámicas en derecho y, especialmente, en derecho codificado es el resultado de una invención que hunde sus raíces en la irrupción europea en la escena musulmana" en DUPRET, B, La sharía, cit. p.89. En estas descripciones se está equiparando por los autores "derecho islámico" y "derecho musulmán". Además nos gustaría añadir que el diccionario de términos islámicos describe la Charía como la Ley revelada o canoníca del Islam, el cuerpo completo de las reglas que gobiernan la vida de los musulmanes que se derivan del Sagrado Corán y de la Sunna. Asimismo el Fiqh es descrito como la ciencia de la charía, la ley del Islam. Jurisprudencia islámica. AL-KHUDRAWI, D., Dictionary,cit. pp. 408, 268.

${ }^{8}$ HALLAQ, W B., Shari'a, theory practice transformations. Cambridge University Press. Cambridge. 2009. p.3.

${ }^{9}$ DUPRET, B, La sharía, cit. pp.18-19.
} 
de los textos sagrados. En nuestro caso, preferimos ceñirnos exclusivamente a la charía como las fuentes sagradas, o Ley islámica y al fiqh como la doctrina, entendida de acuerdo a la explicación ofrecida más arriba de la Enciclopedia Jurídica. Así, la charía se correspondería con el texto inalterable, perteneciendo solo a la doctrina el campo de la interpretación.

Nos parece relevante tener en cuenta que la literatura inglesa habla del fiqh como jurisprudencia islámica, islamic jurisprudence. Y de la metodología del fiqh conocida como usul al-fiqh, como methodology of islamic jurisprudence.

La diferencia terminológica entre el castellano y el inglés deriva del hecho de que en la mayor parte de los países europeos se utiliza el sistema jurídico del Derecho Continental, mientras que aquellos países con influencia inglesa, como pasa con antiguos territorios de sus colonias tienen el sistema jurídico del Derecho Anglosajón o Common Law. La divergencia esencial entre ambos estriba en que el anglosajón se considera un sistema jurisprudencial, ya que las sentencias judiciales son las bases del mismo, tienen carácter vinculante para todos los jueces y crean un precedente judicial o stare decisis. Por su parte, el continental se considera un derecho legal, ya que la ley es la fuente del mismo, las sentencias que otros jueces hayan emitido con anterioridad no tienen carácter vinculante, no sientan precedente, sino que se aceptan como parte de una corriente interpretativa o doctrinal sobre un asunto.

El término islamic jurisprudence se utiliza teniendo en cuenta que el fiqh integra las interpretaciones de los juristas islámicos. Así que podría parecerse en este sentido al sistema jurisprudencial inglés en tanto que se basa en sentencias establecidas, que creemos, que en este caso serían las propias de cada escuela jurídica islámica, que a veces también se describen como escuelas doctrinales (hanafí, malikí, shafi 'í y hanbalí). Esto no implica que siempre sienten precedente y éste sea inamovible, porque gracias a mecanismos como el iytihad ${ }^{10}$ la norma y el fallo judicial pueden cambiar.

Mientras, en castellano utilizamos doctrina porque la interpretación de la ley es algo continuo en el tiempo; sucede lo mismo en el islam, desde la muerte del Profeta hasta nuestros días la ley necesita amoldarse a los tiempos modernos y a situaciones determinadas. De esto se ha encargado y se encarga la doctrina legal/fiqh, de legislar sobre temas en los que no existía legislación previa. Y a su vez también en utilizar normativa existente basándose en muchos autores que habían establecido normas, y entre los que encontramos diferencias doctrinales, dependiendo de la escuela jurídica a la que pertenezca, para aplicarlos a determinados contextos. Sería como una combinación entre un sistema con precedente judicial y otro proclive a una interpretación legal constante.

\footnotetext{
10 "El iytihad se podría considerar, una vez aceptadas las fuentes jurídicas del Islam como válidas para todos los tiempos y espacios, como un esfuerzo creativo pero intelectualmente disciplinado para derivar normas legales de esas fuentes, mientras toma en consideración las variables impuestas por la fluctuación de las circunstancias en las sociedades musulmanas", JABIR AL ALWANI, T, Source methodology in Islamic jurisprudence (Usul al-Fiqh al Islami). International Institute of Islamic thought. Virginia, USA. 1415/1994.p.3. Se considera también como "el sistema de interpretación racional de las fuentes (usul) del derecho islámico (fiqh) con el fin de establecer jurisprudencia que provea soluciones para la aplicación de la charía”. En GÓMEZ GARCÍA, L, Diccionario, cit. pp. 148-149. El Iytihad puede aparecer en varias formas que dependen de una serie de reglas, estas pueden resumirse como: qiyas, istihsan, istislah/maslaha, istishab y otras. Todas pertenecen al mundo de la deducción y aplicación de la ley.
} 
Por todo esto es que a veces se hace uso del vocablo fiqh en castellano, como jurisprudencia islámica, cuando se utiliza el término jurisprudencia de manera más amplia y conlleva una de las descripciones expuestas por el diccionario de la RAE, como un conjunto de sentencias doctrinales y doctrinas que contienen. Es por ello por lo que a veces encontraremos a lo largo de nuestro trabajo el término jurisprudencia en sentido más amplio y que incluye la doctrina.

No es baladí mencionar que la acuñación de términos como Mohamedan law o ley de los mahometanos es una terminología obsoleta que ya no se usa y que no refleja fielmente lo que se entiende por Ley islámica, ya que los musulmanes no sólo creen o siguen al Profeta Muhammad únicamente, sino a todos los profetas judíos y cristianos. Los musulmanes creen en Dios por encima de todo, e idealizar la figura del Profeta o elevarlo a nivel divino, siendo él al que habría que seguir en vez de a Dios, se consideraría kafr, incredulidad o descreimiento; aunque hoy este último término tiene connotaciones diferentes debido al desarrollo del Islam político a lo largo del S.XX. Por ende, Muhammad es el transmisor de la ley divina expresada en el Corán y en la Sunna (en lo relacionado con preceptos religiosos), de ahí que se denomine Ley sagrada o charía.

\section{LA CHARÍA}

La charía, o ley islámica, es un conjunto de preceptos y un código de conducta que se compone tanto de leyes como de nociones morales, cuyo objetivo primordial es guiar la vida de un musulmán en la esfera pública y privada. Otros autores la definen como el nombre colectivo de las leyes del islam incluyendo los sistemas religiosos, litúrgico, ético y los sistemas jurisprudenciales ${ }^{11}$. El ideal ético presentado por el Corán y por el Profeta es el objetivo al que la Charía quiere elevar al individuo individual y socialmente.

En palabras de Francis Lamand:

"Ley islámica y derecho musulmán son inseparables de su fundamento religioso (usul). No se trata de un enlace "artificial" del derecho a la religión como han pretendido algunos orientalistas que no eran juristas. La doctrina jurídica occidental ha considerado a menudo al derecho musulmán como un derecho religioso [...] El Derecho musulmán ha sido elaborado a partir de la Charía por los jurisconsultos y según procedimientos que apelan a la lógica y a la pura reflexión personal [...] Con la Charía y el fiqh estamos en el corazón de la religión. Esto es desconcertante para el espíritu occidental acostumbrado a disociar los dominios de lo religioso y de lo profano, de lo individual y de lo comunitario, de lo privado y lo público. Pero la religión musulmana no es una religión de salvación individual desligada de la sociedad y la política". ${ }^{2}$

\footnotetext{
${ }^{11}$ JABIR AL ALWANI, T, Source methodology, cit. p. 3.

${ }^{12}$ LAMAND, F, "La Charía o Ley Islámica" pp.27-41 en AA.VV., (comp: BALTA, P.), Islam, Civilización y sociedades. Siglo XXI de España editores. Segunda edición. Madrid. 2006. pp. 27-28.
} 
La palabra charía proviene de la raíz trilítera árabe chara'a que significa legislar, ordenar, ${ }^{13}$ y también se puede traducir como "vía directa" hacia un fín. La propia expresión chariyy'a quiere decir, además de ley, un lugar con agua, es decir, un objetivo digno de ser buscado, especialmente en las culturas nómadas de la península arábiga. Es importante resaltar que la palabra chara 'a también significa la "ordenación de la ley a través de la revelación". ${ }^{14}$ La línea divisoria entre la ley y la moralidad es difícil de discernir en la charía, así la Ley Islámica no hace distinción entre lo legal y lo moral, como dice Wael Hallaq "de hecho no hay palabras en árabe, la lingua franca de la ley, para las diferentes nociones moral-legal". ${ }^{15}$

A modo de ejemplo podemos citar que en el Corán se comenta en varias ocasiones que las acciones y los juramentos que se realizan sin malas intenciones, no son tomados en cuenta, como aparece en la sura 5:91: "Allah no os toma en cuenta los juramentos frívolos, pero si os toma en cuenta los juramentos con los que intencionadamente os comprometéis [...]". ${ }^{16}$ De la misma manera, la posibilidad de arrepentimiento y vuelta hacia el camino correcto puede ocurrir en cualquier momento de la vida de un musulmán, en el que si es sincero, Dios reconocerá las buenas acciones en detrimento de las malas. Nótese que hemos mencionado palabras como sinceridad, arrepentimiento e intencionalidad, lo que refleja el grado de importancia del elemento moral dentro de la ley.

La charía se divide entre principios o creencias-aqayid, transaccionesmo'amalat, rituales-'ibadat y castigos-uqubat. Y clasifica las normas sujetas a regulación por la ley en 5 clases: los actos prohibidos-haram, actos punibles, ya que la comisión de los mismos está prohibida, obligatorios-wayib, ${ }^{17}$ acto que si no se comete también es reprobable puesto que es de obligada realización, recomendable-mustahabb, actos neutrales-mubah y actos desaprobados-makruh. Las categorías tercera, cuarta y quinta o son desaprobadas o recompensadas, pero no son sancionadas. En todos estos casos, la norma viene determinada por el tipo de comportamiento del individuo, y es válida porque es una manifestación de la voluntad divina. Al contrario de lo que sucede en el derecho occidental, en el cual la norma es válida porque así lo determina el derecho positivo imperante, que emana de los aparatos del Estado y no tiene por qué coincidir con la voluntad del sujeto obligado. ${ }^{18}$

La ley islámica se desarrollará por mecanismos como el fiqh (doctrina) y los usul al-fiqh (metodología legal), que están basados en la glosa de la charía a través del

\footnotetext{
${ }^{13}$ Otras palabras derivadas de la misma raíz como sharr'a promulgar, dar, hacer y decretar leyes, shar'u Allah decreto de Allah, shar'i legal, legitimo, shar'iyan legalmente, shar'iyah legitimidad, legalidad, musharri' legislador etc. en KHUDRAWI, D, Dictionaty, cit. p. 268.

${ }^{14}$ VV.AA., (ed: AMANAT, A. y GRIFFEL, F.) Shari'a, cit. p. 184. Así también shara'a aparece en varias suras del Corán como puede ser la 42.11. Sura de la Consulta. El Noble Corán, cit. p.804. Aquí es traducida como "os ha legislado".

${ }^{15}$ HALLAQ, W B., An introduction to Islamic Law, Cambridge University Press, United Kingdom2009. p.19.

${ }_{16}^{16}$ El Noble Corán. cit. Sura de la Mesa Servida. 5:91. pp. 193-194. Niyya es la palabra árabe que se traduce como intención.

${ }^{17}$ Otro término para esta categoría puede ser fard, que se divide a su vez en dos tipos, fard 'ayni que supone una obligación individual como puede ser el rezo, peregrinar, el ayuno o el zakat. Y fard kifa' $i$ que implicaría una obligación colectiva, pero es válida si alguien o un grupo la realiza ya que no toda la comunidad puede; como exponente de la obligación colectiva destaca la yihad.

${ }^{18}$ Véase para el tema de la validez de la norma MANDIROLA BRIEUX, P, Introducción al derecho Islámico. Marcial Pons ediciones jurídicas y sociales. Madrid. 1998 .pp.74-76.
} 
razonamiento humano y el uso de herramientas interpretativas como el iytihad. La metodología de los usul al-fiqh se compone de cuatro fuentes principales: el Corán, la Sunna, el iyma'(consenso) y el qiyas (analogía). ${ }^{19}$ Así, aunque la ley islámica se considere inmutable, ya que proviene de Dios, muchas de las normas derivadas serán producto del esfuerzo del hombre, lo que se refleja directamente en la doctrina legal. Es por ello por lo que aquello que sea presto a la deducción humana, en este caso el fiqh, también establece la categoría de lo lícito (halal) y lo ilícito (haram) y las categorías antes mencionadas ${ }^{20}$.

La interpretación de la ley ha sido siempre el tema más espinoso de la jurisprudencia islámica, pues tratar de saber qué es lo que Dios quiere para los humanos en casos determinados que no vienen relatados ni en el Corán ni la Sunna es sumamente complicado.

En general, como dice Joseph Schacht, la Ley Islámica es "la epítome del pensamiento islámico" 21 , el sistema normativo del Islam que como concepto se traduciría en lo que Dios querría que los humanos hicieran, y como contenido sería lo que el ser humano entiende que debe $\operatorname{ser}^{22}$.

La charía se enfrenta hoy a muchos desafíos, entre otros al hecho de que constantemente se identifique los preceptos legales de ésta última con el islam en general, aunque el islam abarca más que el campo legal de la charía, como si los dos términos significaran los mismo. Es una connotación que también ha surgido a lo largo del S.XX y de la que se hacen eco algunos grupos islamistas, además de ser una idea que socialmente está establecida en muchos lugares. Estos intentan darle más "legalidad" y legitimidad a las normas establecidas en distintos territorios, atribuyendo muchas de sus prácticas que tachan de islámicas como aprobadas por la charía o basadas en esta, con el objetivo de convertir dichas costumbres o incluso ciertas interpretaciones, de personas versadas en la ley o no, en obligatorias. De este modo se relega la capacidad de raciocinio del ser humano, que es un requisito indispensable para que cada individuo conozca su propia religión.

Otra de las caras de la moneda es el hecho de que hay autores que consideran que los principios de la charía se derivan siempre de la interpretación humana del Corán y la sunna, así dice Abdullahi Ahmed An-Na'im que "Charía es siempre el producto de la "agencia humana" de los creyentes, un sistema de significados que es construido partiendo de la experiencia humana y de la reflexión, la cual con el tiempo evoluciona hacia un desarrollo más sistemático de acuerdo con una metodología establecida". ${ }^{23}$

\footnotetext{
${ }^{19}$ Existen otras fuentes que se podrían denominar como secundarias, estas son el maslaha/ istislah, istihsan, istishab.Vid.nota al pie 10.

${ }^{20}$ La taxonomía que establece Luz Gómez incluye dentro del fiqh el ahkam al-jamsa (los cinco veredictos): el acto ineludible (fard), obligatorio (wajib), recomendado (mustahab/mandub), tolerado (mubah) y reprobable (makruh). GÓMEZ GARCÍA, L., Diccionario, cit. p.113.

${ }^{21}$ SCHACHT, J, An introduction to Islamic law. Oxford University Press. London 1964. p. 1

${ }^{22}$ Parte de la conferencia impartida en la Universidad Americana de Beirut del Profesor Abdullahi Ahmed An-Na'im el 15/12/2009.

${ }^{23} \mathrm{AN}-\mathrm{NA}$ 'IM, A A, Islam and the secular state negotiating the future of shari'a. Harvard University Press. Cambridge, Massachusetts and London, 2008. cit. pp. 10, 35 y 291. Para el autor, cualquier concepto de la charía se deriva siempre de la interpretación humana del Corán y la Sunna en un contexto histórico particular. Aunque pensamos que dicha descripción se acerca más al concepto que nosotros entendemos por fiqh.
} 
Para el autor "no hay ninguna concepción de la charía que pueda ser siempre una representación eterna o perfecta de las ordenes divinas, simplemente porque las limitaciones de la comprensión y la experiencia humana"24.

Creemos que aunque Ahmed An-Na'im diferencia la charía del fiqh, pensamos que su afirmación respecto a la charía necesita ser estudiada bajo diversos prismas. Debemos analizar qué preceptos coránicos son objeto de deducciones humanas y cuáles no, los versos coránicos cuyo significado es general y vago, y tampoco quedan especificados en la sunna, necesitan del ejercicio intelectual del hombre para derivar normas. Pero si por el contrario, la norma queda claramente establecida en el Corán (qati) esta no es susceptible de cambio alguno. ${ }^{25}$ En general, la norma que queda firmemente establecida en el Corán no se puede cambiar, y no son muchas, alrededor de un diez por ciento. Entonces, cabría decir que las normas de la charía sujetas al estudio y creación de doctrina no son infalibles, pertenecen al terreno del estudio del fiqh, pero este no abarca todas las normas de la ley islámica.

Quizá el autor piense que incluso aquellas normas que ya han sido establecidas en el Corán deben ser entendidas por especialistas que entiendan el contexto determinado en el que fueron reveladas, a pesar de esto, que es tenido en cuenta por los especialistas de la ley, existe normativa legal que es clara en su significado. Otra cosa es que la ley dificulte o facilite la acusación por un crimen que está penalizado en el Corán. Por poner un ejemplo, existe en el Corán el castigo por robar, de este modo "Al ladrón y a la ladrona cortadles la mano en pago lo que hicieron. Escarmiento de Allah; Allah es Poderoso y Sabio"26, a pesar de que el castigo es claro una vez demostrado como muestra esta aleya, no es fácil llegar a dicha conclusión; algo que se ve también en casos como en el del castigo por adulterio, pues se necesitan cuatro testigos. Peters comenta que "en la doctrina hanafí en particular es casi imposible para un ladrón y un fornicador ser sentenciado, a menos de que lo desee y confiese"27. Establecer si se ha cometido un crimen puede ser difícil, lo que es incontestable es que aquello que ya ha sido categorizado como un delito reflejado textualmente en el Corán no se puede cambiar.

Por su parte, la sunna es el segundo componente de la charía, después del Corán. La sunna está formada por ahadiz, o dichos y hechos del profeta. Si los ahadiz registrados en la sunna son las palabras del Profeta transmitidas por los compañeros de Muhammad o sahaba ${ }^{28}$, sobre todo en lo que a temática religiosa se refiere, entonces se considera que tienen un origen divino, el Corán dice respecto al Profeta:

\footnotetext{
${ }_{25}^{24}$ Ibid. p.291.

${ }^{25}$ Si la norma coránica se cambia entonces se contraviene la palabra de Dios, los cambios que se producen intentan realizarse en el marco de la metodología legal.

${ }^{26}$ El Noble Corán, cit., Sura de La Mesa Servida, 5:40. p.181.

${ }^{27}$ PETERS, R, Crime and Punishment in Islamic Law. Theory and Practice from the sixteenth to the twenty-first century. Cambridge University Press. Cambrige, 2005. p.54.

${ }^{28}$ Los Sahaba, cuyo singular es sahabi, son los compañeros de Mahoma. Cualquier persona que abrazó el islam y acompañó al Profeta en algún momento es sahabi, se ha estimado que fueron unas 140.000 personas. La importancia de estos es fundamental ya que el testimonio de sus ahadiz constituirán el isnad o cadena de transmisión que llevará a la recopilación del hadiz. Ver GÓMEZ GARCÍA, L., Diccionario, cit. p.292. Además, los compañeros del Profeta establecerían jurisprudencia a través de métodos como el iyma'a (consenso) y el iytihad. Algunos de estos sahaba fueron los cuatro primeros califas, también designados como Julafa al-Rashidin, lo que viene a significar los califas bien guiados o encaminados. En castellano también se conocen como los califas rachidíes y son Abu Bakr, Omar Ibn Al Jattab, Osman Ibn
} 
"Vuestro compañero no está extraviado en un error. Ni habla movido por el deseo. No es sino una revelación inspirada. Le enseña alguien de gran poder y fortaleza. Que tomó su verdadera forma sobre el horizonte más alto (Gabriel). Y se acercó y se humilló (el Profeta)"

Y del mismo modo:

"Y obedeced a Allah, obedeced al Mensajero y tomad precauciones. Y si os apartáis, sabed que a Nuestro mensajero solo le incumbe hacer llegar el mensaje con claridad". ${ }^{29}$

De este modo, queda claro que las palabras del Profeta tienen inspiración divina (cuando ha recibido la revelación y cuando aclara temática coránica a través de la sunna), la cuestión es saber si las palabras registradas en el hadiz son realmente las del Profeta, pero si así fuera como se cree en las compilaciones de ahadiz más reputadas; entonces no cabría duda. Pero si la fuente que relata dicho hadiz es débil, entonces cabe pensar que puede que no sean las palabras del Profeta, y en este caso el dicho en concreto no tendría ningún origen divino. Y aunque fueran las palabras del Profeta, el matiz con que el jurista entiende el contexto en el que se encuentra dicho hadiz también es de vital importancia para su exégesis y, como afirma $\mathrm{Na} i m$, entonces sí que pertenecería al ámbito de la interpretación humana, a menos de que el consenso de los juristas (iyma'a) entienda que el hadiz en concreto tiene un significado único y claro.

En todo caso, queda patente que todo aquello sujeto a cambio pertenece al ámbito de deducción del fiqh y de los usul al-fiqh a partir de las fuentes principales. En cambio, aquellas normas que no quedan sujetas a la deducción o inferencia de los juristas expertos en la materia es porque ya han quedado suficientemente claras y establecidas en el Corán o la Sunna.

Esta afirmación nos remite al hecho de que se considere también la charía como la ley de Dios/ley islámica y no se confunda el fiqh y toda la legislación islámica en general. Como hemos visto antes, Taha al-Alwani incluye los sistemas jurisprudenciales dentro de la definición de charía. Sabemos que la revelación divina acabó a la muerte del Profeta Muhammad y que la legislación coránica en materia legal como ya comentamos con anterioridad es limitada; entonces pertenece al terreno de la doctrina y su metodología la exégesis de las cuestiones de derecho que se desarrollaron posteriormente en el tiempo, y que tendrán lugar debido a las demandas sociales e históricas del momento. Pensamos que en los casos que se entiende la charía también

\footnotetext{
Affan y 'Ali Ibn Abu Talib. La doctrina clásica del Islam suní establece que el califa tiene autoridad espiritual y política, pero esto ocurriría solo de manera consensuada y de manera excepcional con los cuatro primeros califas (que se autodenominaban Julafa Rasul Allah, vicario del Profeta de Dios ), y a excepción de algún califa abasí que se autodenominó califa de Dios. El chiismo impugna la teoría de los califas suníes y solo tiene en cuenta a Ali (el cuarto de los rachidíes) y a sus descendientes. Tanto las dinastías califales Omeya como la Abasí tendrían califas que se encargarían de velar por el cumplimiento de la charía y el fiqh formulado por los faquíes, esto les dotaba de poder ejecutivo como aplicadores de las leyes, y religioso por su cualidad misma de poseedores de la fe musulmana pero no ostentaban ningún poder espiritual. Según Saint-Prot, los compañeros-sahaba más eminentes son unos sesenta incluidos los cuatro primeros califas. Los Compañeros pertenecen a la primera generación de Salaf, "predecesores" o "ancestros piadosos/píos" (salaf al-salih). Las dos generaciones siguientes fueron los Sucesores o tabi 'un, en SAINT-PROT, C, La tradición islámica de la Reforma. Biblioteca del Islam contemporáneo. Ediciones Bellaterra. 2014. Barcelona.p.33.

${ }^{29}$ El Noble Corán. cit. Sura del Astro. 53:2-8 p.885 y Sura de la Mesa Servida 5:94. p.194.
} 
incluyendo al fiqh es debido a que éste último deriva la normativa legal basándose en el Corán y la sunna, empero nos parece más lógico diferenciarlo.

Si se entiende charía como un todo que abarca de igual modo el fiqh se puede confundir lo que atañe a lo inmutable en materia legal islámica, y a aquello que pertenece al terreno de la interpretación por parte de los profesionales de la ley y que pertenece a la ciencia del figh. Es decir, confundir como inmutable aquello que no tiene porque serlo y que es de necesaria aplicación a contextos sociales determinados.

Por ello, la afirmación actual acerca de la creación de un Estado islámico y la aplicación de la charía como mandato de Dios, de una determinada manera, es un tema muy controvertido, fácilmente cuestionable. Sobre todo porque la ley reflejada en la charía no se puede aplicar a muchos casos que se producen en sociedades actuales, si antes no se deriva la norma. Debido a la confusión e identificación terminológica a la que esto conlleva, pensamos que sería más práctico denominar ley sagrada/islámica/charía estrictamente a lo que abarca los términos Corán y Sunna y referirnos al fiqh con la expresión "doctrina islámica".

Por último, el derecho musulmán o islámico, término también muy extendido, podría ser el equivalente de qanun al-islami ${ }^{30}$ (literalmente, leyes islámicas, recordando que qanun alude también a las leyes emanadas del Estado). Es el derecho al que ha quedado delimitado la potestad de los tribunales islámicos en la actualidad ${ }^{31}$, y del mismo modo no se puede identificar con el término charía en general.

\section{El Corán}

El Corán es el elemento central del Islam en general, como de la ley islámica en particular. El término significa recitación y es considerado verbatim la palabra de Dios, no creada, revelada al Profeta Muhammad a través del arcángel Gabriel, lo que se denomina wahy (revelación divina). ${ }^{32}$ El periodo de la revelación va desde el año 610 hasta la muerte del Profeta Muhammad en el año 632, lo que se refleja en un total de

\footnotetext{
${ }^{30}$ El significado de la palabra qanun es de regulación o el de ley, en general aplicadas por un gobierno, en su origen se intentaba que supliera a la ley islámica en materias insuficientemente reguladas, lo que sería el fiqh pero adaptado al contexto actual, un término más moderno. Qanun también era el derecho producido en el imperio otomano por el poder sultánico. Véase ESPOSTITO, J L., Oxford, cit. p. 252. En este caso añadimos, a modo personal, el vocablo islami, para que se sepa que es una ley como indica la palabra Qanun que está totalmente inserta en las sociedades musulmanas modernas, pero que es a la vez religiosa (lo que tiene que ver con todo lo establecido por las instituciones religiosas islámicas) por eso añadimos este último término. De esta manera se distinguiría y se dejaría de catalogar toda la ley en general como charía.

${ }^{31}$ Vid. la definición de términos: "derecho islámico" y "derecho musulmán”, nota al pie número 7.

${ }^{32}$ En la actualidad existen tres puntos de vista en relación a la naturaleza de la revelación en el mundo islámico: 1) Que el Corán son la palabras de Dios reveladas al Profeta, y este la transmitió como tal; 2) Que el contenido del Corán fue revelado al Profeta y este usó sus palabras para transmitir el mensaje divino, y la $3^{\mathrm{a}}$ y última que el Corán son las palabras del Profeta, y como se considera que tiene una personalidad divina sus palabras son las de Dios. ESMAEILI, H, "The nature and development of law in Islam and the rule of law challenge in the Middle East and the Muslim world". 26 Connecticut Journal of International Law 329-366 (2011). p.347. Existe lo que se denomina wahy zahir que podría traducirse como la traducción expresa, es decir, de Dios al Profeta a través del arcángel Gabriel. Y el wahy batin o revelación interna, que consistiría en la inspiración de conceptos de Dios al Profeta.
} 
total de 114 suras y 6200 versículos o aleyas (ayat) (otros autores, como Kamali, aseveran que son unos 6235). Las primeras están divididas por tamaño, así que el Corán comienza con las suras más largas, con la de la Vaca, y termina con las suras más pequeñas como la sura de los hombres. La primera Sura revelada al Profeta Muhammad fue la sura 96:1 del Coágulo (al'Alaq), y la última aleya revelada fue la de la sura de la Mesa Servida (al-Ma'idah) 5:4 ${ }^{33}$. Y estas, a su vez, se dividen en suras mequíes, las reveladas en el periodo de la vida del Profeta en la Meca, y las medinesas, reveladas durante el tiempo que vivió en Medina, después de la hégira.

Las primeras tienen una temática relacionada con el tawhid (unicidad divina) y la adoración, además de valores como los familiares, la propiedad, etc., mientras las segundas tienen una temática más política, legal, social y económica. Aunque las dos fases de la revelación están intrínsecamente relacionadas, el conocimiento de ambas es crucial para comprender la trascendencia de las suras o versículos que pueden abrogar (nasj) los contenidos legales de otras suras, y las suras que quedan abrogadas (mansuj); éste mismo método se aplica también a los ahadiz.

El lenguaje coránico es particular en el sentido de la narración, tiene una rima y ritmo que hacen su recitación fácil y posee una concinidad poética. Del mismo modo, el arte de la caligrafía islámica trata de representar la lengua coránica lo más bellamente posible, como se puede observar por ejemplo en las transcripciones angulares del estilo cúfico. Los comentarios escritos del Corán comenzarían a aparecer a finales del S.IX. Entre los más conocidos están los de al-Tabari (m.923), al-Razi (m.1209), al-Qurtubi (m.1273), Ibn Khazir (m.1373), al-Suyuty (m.1505) especializados en el tafsir, que consiste en una exégesis del texto coránico para explicar, elucidar y comentar su significado. Lo que requiere a priori un conocimiento del árabe, de la materia jurídica, teológica e histórica importante. No hay que olvidar que el Corán es el origen y el final del Islam, es el centro alrededor del que se mueven todas las disciplinas y la fe musulmana, además de ser un libro de historia, sociología, economía, política, leyes, derecho internacional, es un sistema ético y de comportamiento social. ${ }^{34}$ Su guía es el conocimiento que el hombre necesita para la búsqueda de su felicidad y perfeccionamiento personal, tanto para la vida terrenal como para la del paraíso. ${ }^{35}$

Una vez queda consolidada la versión definitiva del Corán, la que llegará hasta nuestros días, y que se realizó en tiempos del tercer califa Osman Ibn Affan ${ }^{36}$, nunca

\footnotetext{
33 "Hoy os he completado vuestra Practica de Adoración, he culminado Mi bendición sobre vosotros y os he aceptado, complacido, el islam como Práctica de Adoración...”. Práctica de Adoración que en el texto en árabe aparece como dinakum y se traduciría también por religión la primera vez, y la segunda como Islam. "Al ywm akmalat lakum dinukum wa atmatu a laikumni 'amati wa radditu lakum al islam dinan". El Noble Corán. cit. Sura de la Mesa Servida.5:4. p.171. Otros autores señalan que el último versículo revelado fue el 176 de la sura de las mujeres, vid. "Muftis, Fatwas and Islamic Legal Interpretation" en AA.VV (ed: KHALID MASUD, M, MESSICK, B y POWERS S. D) Islamic Legal interpretation. Muftis and their fatwas. Center for Middle Eastern studies, Harvard Studies in Islamic law. Harvard University Press. London. 1996.p.4.

${ }^{34}$ Se consideran cuatro etapas históricas en la ciencia del tafsir, la primera durante el tiempo del Profeta, durante el tiempo de los compañeros, durante el tiempo de la generación siguiente a los primeros compañeros (tabi ‘un), y el tafsir durante la época de la compilación. Vid. IBN ABDUL LATEEF AL MAHMOOD, A., A book on Islamic studies. Kitaab al-mutaalaah. Darussalam. Riyadh. 2010. pp. 110111.

${ }^{35}$ Para un estudio completo del Corán, ver HASHIM KAMALI, M., Principles of islamic jurisprudence. The Islamic texts society. Cambridge, edición 2003. pp 16-58.

${ }^{36}$ Vid. nota al pie 28.
} 
será discutida la autoridad del mismo, no sólo por la potestad conferida al Califa mismo, sino también porque queda establecido por la comunidad musulmana qué es el Corán; así los ulemas ${ }^{37}$ acuerdan que el texto completo del Corán es mutawatir ${ }^{38}$. Hay que recalcar que aunque el Corán queda fijado con Osman, la memorización e inscripciones del mismo en huesos, trozos de cuero y madera entre otros, datan del tiempo del Profeta, por parte de sus compañeros, ya que él no sabía ni leer ni escribir. El mismo Profeta observó el inicio de la transcripción del Corán.

No existen diferentes "coranes", sino siete tipos de lectura del mismo, dependiendo de algunas variaciones en ciertas vocales, esto a veces puede implicar un cambio se sentido en algunas palabras que puede reflejarse en la exégesis de algunos textos. Existen algunas teorías como la desaparición de dos papiros importantes que se cuenta que fueron masticados por una cabra, una teoría comenta que era el papiro en relación a una sanción más fuerte para la comisión de adulterio ${ }^{39}$, y la segunda avalada por los chiíes que señalan que esclarecía que era el Imán Ali el sucesor inmediato del Profeta. No sabemos cuán fidedignas son estas dos posibilidades, en todo caso, si esto ocurrió cuando se estaba unificando los papiros del Corán para su codificación, existían muchos sahaba que habían memorizado el Corán y podrían haber corregido o confirmado estas dos teorías.

Los ámbitos del estudio coránico son esencialmente tres, el primero es el de la teología, Ilm al-kalam (teología dialéctica) dedicada al estudio de al-‘aquida (el credo). El segundo estaría más relacionado con la moral, las buenas y malas obras, normas de conducta, todo imbuido en el campo de la ética Ilm al-ajlaq. Y por último el ámbito de

\footnotetext{
${ }^{37}$ Esta palabra significa exactamente "el que sabe" persona provista de conocimiento, un erudito en el islam y la ley y las respectivas ciencias de esta última, generalmente el término incluye a todos los profesores religiosos, como los Imán, Muftis y Qadis. El singular de esta palabra es 'alim que significa el sabio conocedor, culto. En la era moderna el trabajo de los ulemas ha quedado reducido a la mezquita, la madrasa y algunas instituciones religiosas.

${ }^{38}$ Este término utilizado también para el hadiz, significa sucesión, continuidad, e implica que texto ha sido narrado por un gran número de personas lo que hace casi imposible que sea inventado. Algunos chíes creen que el Corán fue compilado por el imán Ali en tiempos del profeta, como nos confirmó el jeque Afif Naboulsi en la entrevista realizada con él Saida, Líbano, el 20/06/2010. Según Olivier Roy, sólo los chíes discuten la versión oficial del Corán, afirman que el califa Omar eliminó deliberadamente los versículos que mencionan a 'Ali como sucesor nombrado por Muhammad. Del mismo modo, los ibadíes impugnan la azora de José, pues la consideran frívola. En ROY, O., (trad: J. Vivanco), Genealogia del islamismo. Biblioteca del Islam contemporáneo 5. Ediciones Bellaterra. Barcelona. 1996. p.20. Del mismo modo, el Amir Moezzi ha mostrado que el chiismo primitivo estaba convencido de que los Imanes tenían un Corán más completo, en RICHARD, Y., (Trad: J. Vivanco), El Islam Shií. Biblioteca del Islam Contemporáneo. Ediciones Bellaterra. Barcelona. 1996. p.30. En la entrevista realizada con el jeque Sami Jadra, religioso del partido político y resistencia armada de Hezbolá en el Líbano el 20/6/2013, este afirmaba que el Corán, como se conoce desde tiempos de Osman, es el único y al cual se remiten tanto chí́es como suníes.

${ }^{39}$ La lapidación por adulterio no existe en el Corán. Hallaq afirma que aunque el Profeta declaró en un hadiz cien latigazos y un año de destierro como pena por adulterio, más tarde ordenó la lapidación en el caso de un hombre llamado Maiz. HALLAQ W B., A history of Islamic legal theories. An introduction to sunni usul al-fiqh. Cambridge University Press. United Kingdom, 1997. p. 70. Rudolph Peters también comenta que la lapidación aunque no se menciona en el Corán se basa en un hadiz recogido por Asqalani en su obra Bulugh n.1031. PETERS, R., Crime and Punishment, cit. p.60, recoge también el hadiz sobre Maiz que menciona Hallaq en la p.55, pero en este caso Peters especifica que Maiz confesó cuatro veces al Profeta relaciones sexuales no permitidas. Otros autores piensan que la legislación en relación a la lapidación se realizó después del fallecimiento del Profeta, en los tiempos del Califa Omar, en FATOOHI, L., Abrogation in the Qur'an and Islamic Law. A critical study of the concept of "Naskh" and its impact. Routledge. Nueva York. 2013.p. 241.
} 
la ley. Este último se centra esencialmente en las relaciones de Dios con el hombre, las relaciones entre los hombres, leyes que aseguren y defiendan la propagación del islam, las leyes para el desarrollo y protección de la estructura familiar, las leyes comerciales y algunas leyes en materia criminal.

En lo referente a las suras y aleyas que forman la parte legal (al-ahkam ala'maliyya), y que son la base del corpus iuris del Corán, en opinión de Kamali, son cerca de 350 los versículos legales en el Corán, otros autores establecen alrededor de 200 versículos y otros $500 ;{ }^{40}$ pero lo que es evidente es que no es una cantidad muy grande. Como ya mencionamos con anterioridad, solo los textos claros y específicos (jass) del Corán, que se denominan qati, no están expuestos a interpretación, y son alrededor de 180, el resto subyace en el terreno de lo especulativo o zani. Estos últimos se pueden interpretar a través de la sunna y el resto de las fuentes de la metodología de los usul al-fiqh. El iytihad también es una herramienta básica para la interpretación y formulaciones, aunque siempre basadas en los textos sagrados. No obstante, debemos percatarnos de que el terreno de la interpretación es frágil, pues pueden existir diferentes opiniones de los ulemas respecto al mismo tema de análisis o exégesis.

Un elemento fundamental para el estudio del Corán es lo que se denomina Asbab al-nuzul u ocasiones o razones de la revelación, narradas de manera fiable por los compañeros del Profeta, que tuvieron que presenciar la razón relacionada con una revelación o pasaje particular. Ibn Taymiyya decía que: "el conocimiento de la causa de la revelación ayuda a la comprensión del versículo. Ya que, el conocimiento de la causa conlleva al conocimiento del efecto" ${ }^{21}$. El Corán fue revelado gradualmente durante un periodo de 23 años a lo largo de los cuales las circunstancias políticas y sociales eran cambiantes; es por ello por lo que la gradación de las normas se adaptaban a los cambios, además, de no haber sido así, hubiera sido más difícil la aceptación y asimilación del islam. En muchos casos, las razones de la revelación están en relación directa con casos o problemas concretos, de ahí la relevancia del conocimiento del contexto, de este modo, un ejemplo fueron las suras que descendieron para defender la

\footnotetext{
${ }^{40}$ BOTIVEAU, B., "Derecho islámico: de lo político a lo antropológico" pp.45-65. en VV.AA (ed: BORRAS, A. y MERNISSI, S.), El Islam jurídico y Europa, cit. p. 56. En LAWRENCE, B B., introducción en IBN KHALDUN, (Trad. y presentado por Franz Rosenthal con nueva introducción de Bruce, Lawrence B.), Al Muqaddimah., Princeton University Press. New Jersey. Edición 2005. p. XXII. También en HALLAQ W B., Ibid. p.3. Hallaq asevera que los juristas musulmanes así como los eruditos modernos en la materia están de acuerdo en que el Corán contiene unos 500 versículos con contenido legal. Mientras que Coulson afirma que la legislación coránica se despliega como máximo en unos 600 versículos, la inmensa mayoría referidos a deberes religiosos y prácticas rituales de oración, ayuno y peregrinación; no más de aproximadamente 80 versículos tratan de temas legales es el sentido estricto del término. En COULSON, N J., Historia del Derecho Islámico. Biblioteca del Islam Contemporáneo, numero 10. Traducción de María Eugenia Eyras. Barcelona. 1998. p. 22. Garaudy afirma que el Corán sólo contiene 80 versículos que sean prescripciones jurídicas. En materia penal: cinco penas coránicas relacionadas con el robo, la fornicación, la calumnia, el bandidaje y el homicidio. En materia civil: dos prescripciones relacionadas con el comercio y otra relacionada con las deudas. En materia de estado personal, todos los demás versículos "legislativos" formulan reglas concernientes al matrimonio, el divorcio y la herencia. Más del 95\% del Corán trata sobre la fe en Dios, la moral, la "vía recta", fines a seguir para cumplir la voluntad de Dios. En GARAUDY, R., (trad: C. Gardini), Los integrismos, el fundamentalismo en el mundo. Gedisa editorial. Cuarta reimpresión en Barcelona 2001.p.94.

${ }^{41}$ IBN ABDUL LATEEF AL MAHMOOD, A. A book, cit. p. 110.
} 
reputación de 'Aisha, a la sazón tercera esposa del Profeta, que había sido acusada de adulterio. $^{42}$

Además, el conocimiento del contexto de las revelaciones conlleva una capacidad heurística que proporciona información sobre las costumbres de la sociedad árabe del momento, por ello muchas normas quedaron abrogadas en beneficio de prohibiciones o actos permitidos posteriormente. De esta manera, a modo de ejemplo, en un primer momento se rezaba en dirección a Jerusalén, lo que posteriormente se cambió por la dirección a la Meca. Otro ejemplo es que en un primer momento la obligación del rezo (salah) era de dos veces al día, lo que tras la hégira cambió a cinco $^{43}$, o la prohibición de la consumición de bebidas alcohólicas que no se impidió desde el principio.

Hoy día el estudio de los Asbab al-nuzul cobra más relevancia todavía ya que por ejemplo muchos islamistas radicales entienden suras que descendieron para momentos específicos de lucha contra no creyentes, como aplicables tanto a musulmanes como a no musulmanes. O también existe a veces la omisión de las circunstancias que rodean las revelaciones para la interpretación o comprensión del texto sagrado. Este tema tiene una incidencia fundamental para la exégesis del Corán y de la Sunna, y necesita de una disquisición precisa para entender el marco político y social al que hace referencia, lo cual indicará el porqué del comportamiento y acciones del Profeta en muchas circunstancias. Se presenta aquí de nuevo la perpetua nebulosa de la problemática de la interpretación.

Desde el nacimiento del Islam la interpretación del sentido de la ley ha sido el desiderátum de los juristas, las revelaciones dejaron de existir desde la muerte del Profeta, y aunque la glosa de los textos y la metodología es variada, la fuente de las mismas debe remitirse siempre al Corán y la Sunna como bien expresa el versículo 16:89: "Hemos hecho que te descendiera a ti el libro que es una aclaración para cada cosa y una guía, misericordia y buenas noticias para los que se someten (musulmanes) "44. Estar versado en las ciencias coránicas es condición sine qua non para el acceso a la hermenéutica coránica, también se necesita conocer en profundidad la lengua árabe, la diferencia entre tafsir, el sentido evidente de las palabras, y ta'wil la intención o el sentido figurado, los versos generales ( $\left.a^{\prime} \mathrm{mm}\right)$ y específicos (jass),

\footnotetext{
${ }^{42}$ El Noble Corán. cit. Sura de la Luz. suras 24:4, 24:11, 24:12, 24:13, 24:14, 24:15, 24:16. pp. 568 y ss. 'Aisha había salido junto al Profeta en la expedición de banu Mustalaq, a lo largo del camino perdió su collar, y tratando de encontrarlo la expedición partió sin ella darse cuenta. Quedó a la espera hasta que Safwan b. Mutal le ofreció su camello y la llevó de nuevo con la expedición. Al verla llegar con un hombre se extendió el rumor por una parte de la población sobre su reputación. Al mes descendieron las suras en su defensa. El Islam pena la acusación de adulterio (zina), si éste no queda probado con al menos cuatro testigos. Éste es uno de los puntos críticos y que diferencian a los chí́es y suníes, pues los primeros critican el comportamiento de "Aisha no solo en esta circunstancia sino por su participación en la batalla del camello en contra del Califa 'Ali. Este incidente en relación a la acusación de 'Aisha por adulterio se conoce también como hadizat al-ifk.

${ }^{43}$ IBN KATHIR, (trad:N. Eweiss, ed: S. Cook) Moajiset el Nabi (the miracles of the Prophet). Dar al Manara. Egipto, 2002. pp. 200 y ss. Aquí en base a un hadiz narrado por al-Bujari, Ibn Kazir nos cuenta el viaje del Profeta la noche que ascendió a los 7 cielos, el viaje nocturno de al-Israa y al-Mi'ray. En cada cielo vió a un profeta, en el primero a Adán (Adam), en el segundo a Juan (Yahya), en el tercero a José (Yusuf), en el cuarto a Idris, en el quinto a Aron (Harun), en el sexto a Moisés (Musa) y en el séptimo a Abraham (Ibrahim). En este viaje Dios encomendó al Profeta que el salat debía realizarse cinco veces al día.

${ }^{44}$ El Noble Corán. Sura de la Abeja. cit. 16:89.pp. 439-440.
} 
versículos independientes del resto del Corán y los dependientes (mutlaq-muqayyad), el significado explícito (mafhum) y el alegórico (majaz), ${ }^{45}$ entre otros.

El Corán como bien indica Muhammad Iqbal tiene como "principal objetivo despertar en el hombre una conciencia superior de su relación con Dios y con el Universo" ${ }^{46}$, esta se da con el conocimiento del Corán mismo, la posición del hombre dentro de su sociedad, y el entendimiento de la misma. El Corán supondrá un elemento innovador en muchos sentidos, pero también implicará la continuidad de costumbres y normas pre-islámicas; este es uno de los aspectos que comentamos anteriormente al referirnos a la gradación.

\section{La Sunna}

La sunna es la segunda fuente de la charía, es fundamental dentro de la tradición islámica, pues no sólo completa el estudio del Corán sino que además es un registro de la vida del Profeta Muhammad, lo que se denomina Sira. ${ }^{47}$ Literalmente la palabra significa camino, vía, una manera de vivir. Antes de adquirir la connotación histórica, política, económica y legal específicamente aplicada al Profeta Muhammad, al mundo islámico y la Umma (comunidad islámica), el término tenía otra serie de connotaciones previas.

En la época preislámica o yahiliya ${ }^{48}$ el término sunna era utilizado para indicar la práctica establecida de la comunidad o costumbre, de este modo Kamali indica que cada tribu de la Arabia preislámica tenía su propia sunna, que consideraban la base de su identidad y orgullo ${ }^{49}$. Con el mismo sentido, la palabra sunna aparece en el Corán dieciséis veces ${ }^{50}$, y aunque no aparezca la referencia sunnat al-Nabi (la Sunna del Profeta), o sunnat Muhammad explícitamente, se entiende que por el reconocimiento expreso que el Corán hace del Profeta y su conducta, esta debe ser tenida en cuenta por los musulmanes. ${ }^{51}$

\footnotetext{
${ }^{45}$ KNUT, V., Between God and the Sultan. A history of Islamic law. Hurst and Company. London.2005 pp.34-35

${ }_{46}$ IQBAL, M., La reconstrucción del pensamiento religioso en el Islam. Trotta, Madrid. 2002. p.156

${ }^{47}$ La Sira de Ibn Hisham es la más conocida sobre el Profeta, y es la versión estándar revisada de la biografía del Profeta realizada por Ibn Ishaq.

48 Término que designa literalmente la época de la "ignorancia" antes de la llegada del Islam.

${ }^{49}$ HASHIM KAMALI, M. Principles, cit. p.58.

${ }^{50}$ AKAR, S., But if you desire God and his Messenger. The concept of choice in sahih al-Bukhari. Studia Orientalia, Vol.102. Finnish Oriental Society. University of Helsinky. Helsinki. 2006. p. 25. En los versículos 33:38 (Sura de los Coligados), 40:84 (Sura del Perdonador) y 48:23 (Sura de la Conquista), haciendo mención a la sunnat Allah. También en 18:54 (Sura de la Caverna) hablando de sunnati alawalin, que se traduciría como sunna de los antiguos. Kamali añade las suras 17:77 (Sura del Viaje Nocturno) y 3:137( Sura de la Familia de Imran). Ibid. p.58

${ }^{51}$ Existe un hadiz citado por Malik que registra al Profeta diciendo: "He dejado entre vosotros dos cosas, mientras os mantengáis apegados a ellas no iréis extraviados: el Libro de Dios y la sunna de Su Profeta" en DUTTON, Y., The origins of Islamic law. The Qur'an, the Muwatta and Madinan Amal. Curzon Press. Richmond, 1999. p.157. También la sura 24:52 del Corán dice: "Di: obedeced a Allah y obedeced al Mensajero..." y la Sura de la Luz, 33:21: "Realmente en el Mensajero tenemos un hermoso ejemplo para quien tenga esperanza en Allah y el Ultimo Día y recuerde mucho a Allah” en El Noble Corán. cit. pp.578-579 y en la Sura de los Coligados, 33:21. p.688. También la Sura de las Mujeres, 4:58. p.141 que dice "Vosotros que creéis obedeced a Allah, obedeced al Mensajero y a aquellos de vosotros que tengan
} 
El hecho es que la sunna entendida como costumbre y su práctica referida a los usos de los sahaba, como pueden ser los primeros califas ${ }^{52}$ irá paralela en el tiempo con la sunna del Profeta, hasta que esta última se institucionalice completamente. Esto no ocurrirá inmediatamente sino que aunque se supone introducida hacia finales del primer siglo en la teoría legal, no será hasta finales del siglo segundo y en concreto con el Imán al-Shafi' $i$, cuando el término sunna quede totalmente restringido a la sunna del Profeta. A lo largo de este periodo técnicas como el musnad para la autenticación de los ahadiz, a través de una cadena de autoridad que llega al Profeta y las compilaciones de los mismos, serán básicas para el establecimiento del criterio de la sunna y su veracidad ${ }^{53}$.

Lo que parece claro es que hasta el establecimiento del término sunna del Profeta o sunna tal como se entiende hoy, existían otros significados de la palabra, distintos del de sunnat al-Nabi. Esta siempre fue considerada como un modelo a seguir entre los musulmanes, de ahí que muchas de las costumbres se han heredado a través de prácticas observadas en el propio Profeta. Constan ahadiz que corroboran esta posición como el citado por Mawardi, donde el Profeta preguntó a Mu'adh:

“¿En qué basarías tus juicios? En el libro de Dios, respondió. El Profeta dijo: y supón que no encuentras lo que necesitas en él. Mu'adh contestó: entonces en la costumbre del Profeta de Dios. Y dijo el Profeta: y supón que no encuentras lo que necesitas. Y contestó de nuevo, usaré mi propio juicio. El Profeta dijo: Alabado sea Allah quien ha guiado al mensajero Su Profeta a lo que le complace a Él y a su Profeta",54.

Una vez sistematizado y consolidado el concepto cabe aclarar qué significa exactamente, así, se entiende por sunna todo aquello narrado por el Profeta, sus actos, dichos, conducta normativa; todo esto queda establecido en tres bloques diferenciados: sunnatu'l-fi'l o lo que hizo el Profeta, sunnatu'l qawl o lo que ordenó el Profeta y sunnatu'l-Taqrir o aquello dicho o hecho en presencia del Profeta, y que no estaba

autoridad..." como también la Sura de la Familia de Imran, 3:32.p.86: "Di: obedeced a Allah y al Mensajero pero si os apartáis...Ciertamente Allah no ama a los que reniegan”. Vid. también SEMAAN, Khalil, Ash-Shafi'is Risalah: Basic Ideas. Arthur Jeffery Memorial Monographs No.1. Publicado por Muhammad Ashraf Kashmiri Bazar, Ashraf Press, Lahore. Pakistán. 1961. p. 24.

${ }^{52}$ Schacht observa que sunna en el contexto original islámico tiene connotaciones políticas más que legales, se refiere a la política y administración del califa. El concepto "sunna del Profeta" no se identificaba todavía con un conjunto de normas positivas pero proveía un enlace doctrinal entre la "sunna de Abu Bakr y Omar y el Corán...” en SCHACHT, J., An Introduction, cit. pp. 17-18.

${ }^{53}$ Las compilaciones se consideran Al-Arba'ah: cuatro compiladores de ahadiz, Abu Dawud, Nasa'i, Tirmidhi e Ibn Majah. Al-Jamsah: los cinco compiladores de ahadiz, Abu Dawud, Nasa'i, Tirmidhi e Ibn Majah y Ahmad. As-Sab'ah: los siete compiladores de ahadiz: Bujari, Muslim, Abu Dawud, Nasa'i, Tirmidhi e Ibn Majah y Ahmad. Y As-Sahih As-sittah: los seis libros de ahadiz y en general las compilaciones a las que más se hacen referencia, Bujari Muslim, Abu Dawud, Nasa'i, Tirmidhi e Ibn Majah. No hay que olvidar que las colecciones de hadiz del Imán Malik y la del imán Ahmad Ibn Hambal también son consideradas importantes. Vid. TAQUI-UD-DIN AL-HILALI, M., y MUHSIN KHAN, M., The Noble Qur'an. Darussalam. Arabia Saudí, Riyadh. 2002. pp.733 y ss. Un factor a observar es que no todos los compiladores contaran con el mismo número de ahadiz, así por ejemplo, el Imán Ahmad recogió 30.000 ahadiz, atestiguados entre unos 700 compañeros del Profeta, y Bujari reconoce legítimos 8000 ahadiz de un total de 300.000 que se conocían, ver MANDIROLA BRIEUX, P., Introducción, cit. p. 62

54 Al Mawardi. (Trad: W. H.Wahba), The ordinances of government. Al-Ahkam al-Sultaniyya w'alWilayat al-Diniyya.. Garnet Publishing. UK.2006. p.74. Este hadiz no sólo relata que las fuentes principales en materia de ley son el Corán y la sunna, sino que además corrobora la importancia del iytihad y el juicio y esfuerzo personal investigador. 
prohibido por él, lo que aprobó tácitamente y también se incluye algunos dichos de los compañeros del Profeta. Aquello que el Profeta ordenó enfáticamente se denomina sunnatu'l Huda o Sunna de la guía, o sunnatu'l-Mu'akkadah, pero aquello que no ordenó se considera sunna ghair Muakkadah ${ }^{55}$. Las palabras del Profeta quedaron registradas por sus compañeros, dicho registro se considera fiable puesto que fue realizado por los compañeros más cercanos al Profeta que le conocían bien, así como también entendían el contexto en el que las normas de la sunna se desarrollaban. De los actos realizados por Muhammad no sólo muchos quedaron registrados por escrito, sino que de manera oral se transmitieron para ser realizados de la misma manera que el Profeta, como cuando se presenciaba al profeta peregrinando o rezando.

Dentro de la sunna se encuentran las materias consideradas legales o sunna tashri'iyya, y las que no se encuentran dentro del ámbito de lo legal o sunna gharyr tashri ‘iyya. En ésta última no todos los actos tienen que ser de obligado cumplimiento. La sunna legal es más complicada de analizar, consiste en la conducta ejemplar del profeta, dichos, sentencias aprobadas que forman parte de la charía, como en la capacidad de explicación de aquellos versos coránicos que legislan de manera vaga y general o que son ambiguos; este tipo de sunna es difícil de analizar, y sobre todo conlleva complicaciones a la hora de interpretarla, así:

"Para distinguir la sunna legal de la no legal es necesario para el muytahid ascender al propósito original y el contexto en el cual una norma particular de la sunna se elaboró, y si se designó para establecer una norma legal general [...] la ausencia de información adecuada y criterio en el cual se determina lo circunstancial y la sunna no legal de lo que constituye la ley general data desde los tiempos de los sahaba. La dificultad ha persistido desde entonces y es debido principalmente a la corta y falta de información adecuada por lo que el desacuerdo ha surgido entre los ulemas sobre la interpretación de la sunna". 56

Hay que tener en cuenta que el Profeta actuará como persona con sus hábitos particulares y también como cabeza del Estado, imán o juez; el discernimiento del contexto es vital para su comprensión y análisis, pues la interpretación actual de este tipo de sunna también adolece de la falta de aprehensión de este tipo de circunstancias.

El elemento más particular de la sunna es el hadiz, pues no solo corroboran la autenticidad de la sunna, si son auténticos, si no que narran el momento histórico, político y social de la época del Profeta. Por supuesto hubo un momento en el que la proliferación y fabricación de ahadiz fue enorme, a lo que la ciencia del hadiz se opuso e intentó depurar hasta la composición de las compilaciones de hadiz consideradas como auténticas.

Es de suma importancia no confundir sunna con hadiz, aunque con el tiempo se hayan convertido casi en vocablos sinónimos. La diferencia radicaría en que "el hadiz es la narración de la conducta del Profeta, mientras que sunna es el ejemplo de la ley que

\footnotetext{
${ }^{55}$ AL-KHUDRAWI, D., Dictionary, cit. p. 254.

${ }^{56}$ HASHIM KAMALI, M., Principles, cit. p. 73.
} 
se deduce de ella. El hadiz, en este sentido, es el vehículo de la sunna. "57 Una vez ambos conceptos quedaron limitados exclusivamente a la sunna y hadiz del Profeta, comenzaron a utilizarse como equivalentes. Aunque autores como Dutton piensan que los términos siguen siendo bastante distintos, ya que la sunna puede, o no, ser registrada por el hadiz, y que el hadiz puede o no registrar sunna. ${ }^{58}$

La autenticidad del hadiz ha sido ampliamente discutida por los estudiosos de la materia, llamados muhaddizun. Para que un hadiz sea aceptado como un verdadero relato proveniente del Profeta, los muhaddizun deben confirmar que se trata de un hadiz musnad $^{59}$, es decir, que cuenta con fundamento o apoyo. Para ello, deben estudiar principalmente la cadena de transmisores conocida como isnad ${ }^{60}$. Si el hadiz es el elemento principal legitimador de la sunna, entonces la veracidad de este es de suma importancia, teniendo en cuenta que lo que dice el Profeta se entiende como inspiración divina y porque lo que diga el Profeta será una conducta y una norma a seguir. Los ahadiz son clasificados en varias categorías, una vez descartados los que son considerados falsos, ya sea por la falta de credibilidad del transmisor, o porque las fechas se contradicen, o porque el hadiz es contrario a una norma coránica, o por el lenguaje no sea acorde del texto (matn), entre otras razones. Existen ahadiz que por su inclinación política también indicarán que no son dignos de confianza, como los que reflejan acusaciones mutuas entre chiíes y suníes; como pueden ser los ahadiz que atacan a los cuatro primero califas, etc.

Los ahadiz se catalogan como continuos (muttasil) y discontinuos (ghayr mutassil). Los continuos cuyo isnad está conectado ininterrumpidamente hasta llegar al Profeta son, mutawatir, mashhur y ahad. ${ }^{61} \mathrm{Y}$ los discontinuos cuya cadena de

\footnotetext{
${ }^{57}$ Ibid. p.61. Vid. un estudio completo sobre el hadiz pp.62-110. Es interesante mencionar que en todas las veces que la palabra hadiz aparece en el Corán, en ningún caso se remite exclusivamente al hadiz del Profeta. En inglés y en castellano se encuentra también la palabra "tradición" para hablar de hadiz.

${ }_{58}^{58}$ DUTTON, Y., The origins, cit. p.168.

${ }^{59}$ La compilación de ahadiz realizada por el Imán Ahmad Ibn Hambal se denomina también Musnad. Makdisi comenta sobre el término muhaddiz, "que éste no deriva de ahl al-Hadiz. Muhaddiz significa un experto en hadiz. Este experto puede ser racionalista o tradicionalista. Por ello para evitar ambigüedad se refiere a los muhaddiz como tradicionistas (no necesariamente tradicionalistas como opuestos a los racionalistas). No hay un término para un solo partidario de la tradición. Puede ser un jurisconsulto (alfaquí) o un tradicionista (muhaddiz) que se dice que es "de los partidarios de la tradición" (un tradicionalista), distinguiéndolo de los partidarios del kalam (un racionalista)" En MAKDISI, G., "Ash'ari and the Ash'arites in Islamic Religious History I". Studia Islamica.N.17. (1962).pp.37-80. en http://www.academia.edu/7491514/6 Ash\%CA\%BFar\%C4\%AB and the Asharites in Islamic Religio us_History-I pp.48-52. Epígrafe de "some theological terminology". $\bar{Y}$ en MAKDISI, $\overline{\mathrm{G}}$., Religion, Law and Learning in Classical Islam, Ashgate, VARIOURUM, London, 1986. p.49.

${ }^{60}$ El isnad también incluye el nombre de la persona que transmitió el hadiz, el compañero que escuchó o vió al Profeta, y el compilador, además del texto o matn. La autenticidad del hadiz requiere un isnad fiable. Vid. ZAMAN, I., "The science of Rijal as a method in the study of hadiths" Journal of Islamic Studies 5:1. pp.1-34 en https://asimiqbal2nd.files.wordpress.com/2009/06/thescienceofrijal.pdf. Así como su tesis doctoral "The evolution of a hadith: transmission, growth and the science of Rijal in a hadiz of $\begin{array}{lccc}\text { SA“AD } & \text { B. } & \text { ABI } & \text { WAQQAS” } \\ \text { file:///C:/Users/alg/Downloads/Zaman_Iftikhar_The\%20Evolution_ofa\%20_Hadith.pdf }\end{array}$

${ }^{61}$ Mutawattir significa continuo o consecutivo, implica que un hadiz ha sido narrado por un número indefinido de personas a través de las tres primeras generaciones de musulmanes, se sabe que son muchas, por ello la posibilidad de que hayan acordado una mentira es prácticamente imposible. Este tipo de hadiz siempre lleva consigo un conocimiento certero. El mutawattir puede ser textual es decir que las narraciones contienen palabras idénticas, o de significado, se concuerda con el mismo pero con diferentes palabras. Mashhur: hadiz narrado desde un sahaba hasta varios, y llega a ser tan conocido que el número de personas se vuelve indefinido, su veracidad recae en el hecho de que transmiten en la primera y
} 
transmisión se interrumpe en algún momento sin extenderse enteramente hasta llegar al Profeta, se denominan como mursal, mu'dal y munqati. ${ }^{62}$ Kamali distingue también categorías teniendo en cuenta los narradores del hadiz, la primera serían los mismos compañeros del Profeta, la segunda los thiqat thabitun, personas de alta estima respetadas y en las que se deposita plena confianza, la tercera thiqat o aquellos en los que también se confía pero en menor grado que los dos primeros; la cuarta denominada saduq o verdadero, se dice de alguien al que se le desconoce cualquier tipo de invención o error grave; sexta o maqbul o aceptado, ya que no hay ninguna prueba en contra de su fiabilidad; y séptimo y último majhul o narrador desconocido, dentro de esta categoría se pueden encontrar también los fusaq, o personas sospechosas de forjar mentiras. Las tres primeras categorías implican que un hadiz es sahih o correcto y su isnad llega hasta el Profeta; el hadiz hasan implica que este pertenece a las categorías cuarta, quinta y sexta, y aquellos ahadiz considerados débiles o da'if se debe a que su cadena de transmisión no pertenece a narradores de la categoría de sahih o hassan ${ }^{63}$.

Se suele acreditar al Califa Omar Ibn Abd al-Aziz, conocido también como Omar II, nieto del segundo califa tras la muerte del Profeta, Omar ibn al-Jattab, como el primero en haber ordenado la primera colección y documentación de hadiz de manera oficial. En consecuencia, escribió lo siguiente a Abu Baker Ibn Muhammad Ibn Hazm: "Colecciona lo que puedas del ahadiz del Mensajero de Dios y escríbelo; temo que ese conocimiento puede perderse y los eruditos puedan disminuir" ${ }^{\prime 64}$. Al contrario que su abuelo, que prefería que un tiempo prudencial hubiera pasado antes de reflejar los ahadiz por escrito y que comenzaran a ponerse en circulación, le preocupaba que la gente atribuyera al hadiz más importancia que al Corán.

Del mismo modo que con el Islam en general, el urf o la costumbre, es algo que tampoco pudo eludir el hadiz, que no podía salir incólume de la presión y el peso histórico de la sociedad árabe tribal de la época, de modo que la costumbre se dejará notar en las narraciones escritas.

La obsesión por dar legitimidad al hadiz es algo que se entiende, ya que la interpretación que de los mismos se realice derivará posteriormente en leyes, que dependen de su credibilidad. Así una vez obtenida esta por el valor atribuido al ser estudiadas y registradas en las compilaciones canónicas, hay que ser críticos para entender que en las mismas aunque todos los hadiz se consideran sahih, otras registran también hadiz da'if.

segunda generación después de la muerte del Profeta. Ahad: este al contrario del mutawattir no implica un conocimiento certero, ya que es narrado por una persona que no llega a completar todos los requisitos para ser mutawattir.

62 Mursal: hadiz cuya cadena de transmisión es incompleta, solo llega hasta la segunda generación después del Profeta. Mu'dal: cualquier hadiz en el cual no se encuentran dos o más narradores consecutivos. Munqati: hadiz en el que la autoridad que narra el hadiz es desconocida en un momento determinado de la cadena de autoridad, o hadiz en el que un narrador anónimo es mencionado.

${ }^{63}$ KAMALI HASHIM, M., Principles, cit. pp. 110-111. Vid. VIKOR, K., Between God, cit. pp. 42-43, AKAR, S., But if you desire God, cit. pp. 167-168, y AZAMI, M., "Hadiz: rules for acceptance and transmission" en The Place of Hadih in Islam. The Muslim Students Association of the United States and Canada. International Islamic Publishing house. Seminar on the 11 june of 1975. Arabia Saudi. pp.19-23.

${ }^{64}$ ALI NADWI, S A., (Trad. and edited: A. Salahi), Hadiz status \& Role. An introduction to the Prophet's tradition.. UK Islamic Academy. Unated Kingdom. 2005. p.17. 
En el mundo islámico se es tendente a decir, "qala al-Rasul" ha dicho el Mensajero, esto o lo otro; esto no se puede decir arbitrariamente, se debe hablar con precisión, pues a veces se nombran ahadiz parecidos con diferentes palabras aunque el significado sea parecido, serían como transmisiones conceptuales, entonces no son las palabras exactas del Profeta. Además solo los ahadiz que se han transmitido como mutawattir comportan lo que se denomina certeza del conocimiento (yakin), ${ }^{65}$ y los que no son mutawattir son ahad y no reflejan este tipo de certeza. Lo que está claro es que son pocos los ahadiz transmitidos como mutawattir narrados con las mismas palabras y que todos los ahadiz de esta categoría son sahih, pero no viceversa. El conocimiento de la ciencia que trata el hadiz es cardinal.

Haciendo una sucinta sinopsis y si tomamos la sunna y el hadiz como un todo, entonces la sunna tiene como objetivo principal complementar al Corán y su importancia viene dada por el hecho de que Dios incita a que la palabra y el ejemplo del Profeta sean escuchados. La sunna no puede derogar ninguna normativa coránica, puesto que es la palabra del Dios, las normas dictadas por el Profeta que corresponden con el Corán y lo corroboran constituye leyes obligatorias, además la sunna se encarga de especificar muchas normas del Corán que tienen un carácter más general. Aunque es considerada el segundo precepto de la charía, la sunna no se entiende separada del Corán y en algunos casos se les considera al mismo nivel. ${ }^{66}$

Una vez analizados los componentes fundamentales de la Charía, podemos afirmar que ésta en su totalidad tiene como finalidad el interés común de todos los musulmanes, sea en esta vida o en la otra, y para salvaguardarlos necesita alcanzar tres objetivos (maqasid): lo indispensable (daruriyyat), necesario (hajiyyat) y lo beneficial

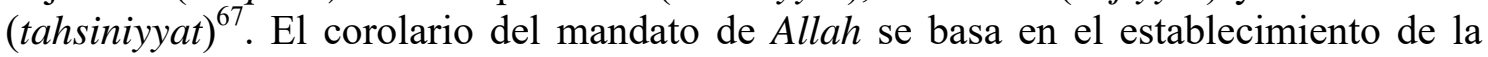
justicia social y económica, la compasión entre seres humanos, gobierno y pueblo, en la regulación de la umma (comunidad islámica) dentro del marco del islam; donde los ordenamientos divinos se pongan en práctica a través de las leyes, cuyo primer jurista, el Profeta Muhammad, se encargo de transmitir con el Corán y completar con su sunna. El máximo exponente de este fin se encuentra en la sura 3:104: "para que de vosotros surja una comunidad que llame al bien, ordene lo reconocido en impida lo reprobable. Estos son los que cosecharan el éxito" $"$.

\footnotetext{
${ }^{65}$ Incluso este tipo de hadiz mutawattir tiene una autoridad equivalente a la del Corán. Vid. KAMALI, HASHIM, M., Principles, cit. p. 94.

${ }^{66}$ En la entrevista realizada a Omar Bakri (fundador del movimiento de los muhayirun) el 18/3/2009, confirmaba que para los salafistas el Corán y la sunna es lo mismo. Para ellos la sunna es la del Profeta, y la interpretación de la sunna por los sahaba. Además de las seis compilaciones ortodoxas del hadiz, tienen en cuenta otras cuatro compilaciones denominadas hadiz de los salaf (estas son Sahih al-sahabi, Hadiz al manqufa, Issafa fi hayat al sahabba y Ussud el gaba fi hayat al sahaba). Del mismo modo, para algunos autores tanto el Corán como el hadiz son la revelación de Dios, Vid. AKAR, S., But if you desire God, cit. p. 30 .

${ }^{67}$ HALLAQ, W.B. Y LITTLE, D.P. "The primacy of the Qur'an in Shatibi's legal theory", Islamic studies presented to Charles J. Adams. Leiden 1991. p. 69-90 en HALLAQ, W B., Law and Legal theory in classical and Medieval Islam. VARIORUM. Aldershot, Hampshire. 1994. p.84.

${ }^{68}$ El Noble Corán. cit. Sura de la familia de Imran.p. 100. Wa attakun minkum ummatun yad'una ila al jair wa yamurun bil ma'rufi wa yanhuna 'an el munkar wa ulaikahum el muflihun. También en 3:110.p. 101.
} 


\section{EL FIQH}

La actividad humana e intelectual consistente en el estudio de la Charía, como hemos comentado, se denomina figh. La palabra significa literalmente "entendimiento o conocimiento", por lo que el fiqh es la ciencia de estudio de la ley divina. Su propio significado refleja la importancia del 'ilm (conocimiento) a la hora de estudiar el Corán y la sunna. El conocimiento constituye la base esencial del intelecto que necesita comprender o intentar averiguar la voluntad de Dios en la tierra; existe un hadiz del Profeta que dice: "A quien Allah le desea el bien, Él le da el fiqh de la religión". ${ }^{69}$ Para los juristas musulmanes (también se les puede denominar alfaquíes, especialistas en fiqh), el 'ilm es el esqueleto del islam. ${ }^{70}$ Este conocimiento implica una responsabilidad religiosa y general, fard qifaya, para que todos los musulmanes sean conscientes de su propia religión y entiendan cómo se deben aplicar sus principios, la ignorancia en este terreno produce malentendidos e interpretaciones erróneas.

El hombre debe aplicar la sensibilidad que le atribuye la percepción necesaria para, como dice Ibn Jaldun, dotarse de la capacidad de pensar. Esta capacidad se compone esencialmente de percepciones, intelecto experimental e intelecto especulativo que elevan al hombre a la perfección dentro de su realidad, y se convierte en intelecto y alma perceptiva, esto según el autor es el significado de la realidad humana. ${ }^{71}$ Vemos como Ibn Jaldún entiende el principio islámico del 'ilm como fundamental para entender la realidad humana, en consonancia con los principios islámicos, así la capacidad de pensar y razonar son principios básicos en el Islam.

En consecuencia, la doctrina islámica, es decir, el fiqh, abarcará todo el cuerpo de leyes deducidas de las fuentes de la ley islámica sagrada, cubriendo todo tipo de situaciones específicas que no trata la Charía (Corán y la sunna). Por esta razón, se considera al fiqh una ciencia falible pues la interpretación recae sobre el ser humano, mientras que la Charía se considera inmutable. Aunque el fiqh tiene como finalidad la deducción de las leyes, este no sólo se remite al derecho sino también a lo relacionado con el culto y la moral. La adaptación a las demandas sociales es vital, puesto que uno de los maqasid o principios u objetivos islámicos de la Charía son el bien y el beneficio general de la comunidad, el texto debe tener en cuenta los cambios que se suceden en las sociedades actuales, para que los musulmanes puedan vivir dentro de un marco legal que sea compatible con su propia realidad.

La doctrina existe indisolublemente unida a la metodología de su estudio, que provee las herramientas necesarias para el análisis exhaustivo de las fuentes sagradas, esta metodología como ya hemos dicho se denomina usul al fiqh.

\footnotetext{
69 PHILIPS, A A B., The evolution of fiqh. Islamic Law \& the Madh-habs. International Islamic Publishing House. New revised edition 3. Riyadh. 2006. p. 15.

${ }^{70}$ Para el Imán al-Shafi‘i, el 'ilm es de dos tipos, el primero que puede ser encontrado en el Corán y la Sunna y el cual los musulmanes conocen, como la oración, ayuno en Ramadan, ...y el segundo que implica que sólo los juristas cualificados pueden extraer de los textos sagrados, trata aspectos técnicos y especializados de la ley. Del mismo modo define 'ilm como el conocimiento de la ley divina al que se puede llegar a través de la analogía o qiyas. Vid. HALLAQ, W B., "On the origins on the controversy about the existence of mujtahids and the gate of ijtihad" Studia Islamica 63. Paris .1986. pp. 129-141 en HALLAQ, W B., Law and Legal theory, cit. p. 131.

${ }^{71}$ IBN KHALDUN, Al Muqaddimah, cit. pp.333-334. Para Ibn Jaldun cuando las ciudades del Islam comenzaron a crecer el analfabetismo desapareció entre los árabes por su constante ocupación con el Corán. Las personas que leían el Corán pasarán a llamarse juristas y eruditos religiosos. p. 345.
} 
El rol actual de la jurisprudencia (y su doctrina) es la aclimatación de la teoría clásica de la ley islámica a los cánones sociales y políticos actuales. A pesar de los cambios históricos, el fiqh no ha devenido en derecho civil y el Corán y la sunna no constituyen un código de leyes como tal, sino que hay que acudir a la jurisprudencia para entender las leyes derivadas de la misma que deben ser aplicadas. Aplicar las leyes de la Charía sin que sean antes filtradas y comprendidas por medio del fiqh supone una entelequia que provocaría un estado monolítico de la ley.

\section{CONCLUSIÓN}

A partir del S.XIX, el mundo islámico va a sufrir una aculturación jurídica, que se va desarrollar a caballo entre el derecho foráneo que se va a imponer en estos países y la jurisprudencia islámica. Este encuentro, generador de tensiones en distintos ámbitos como el político, económico, social y jurídico, provocará la adecuación de una manera u otra de ambos, y se traducirá, tras la caída del Imperio Otomano, en la reducción de la autonomía y potestad de los tribunales islámicos y del fiqh. De este modo, las leyes fijas establecidas en la ley islámica y aquellas derivadas por el fiqh quedarán relegadas al ámbito del estatuto personal, los tribunales islámicos aplicarán la ley que se limitará a los derechos de familia: entre los que se encuentran asuntos como la herencia, el matrimonio, el divorcio y la tutela de los menores. Históricamente, el poder de los ulemas y su capacidad para dominar el terreno religioso se había mantenido lejos de la autoridad de las instituciones políticas y sus regentes. Esto cambia con los nuevos códigos surgidos de la colonización, en los que los ulemas quedan relegados y deben aceptar el nuevo escenario de manera consensuada para evitar conflictos.

La modernidad va a traer consigo una lectura distinta de la charía y el fiqh que no había existido con anterioridad. Así, podemos comenzar diciendo que "la noción de la ley islámica como un código para ser aplicado por la autoridad pública es moderno: en la época clásica, la ley islámica es más cercana a un proceso que a un código" ${ }^{72}$

Parte de este cambio conceptual viene impuesto por la empresa colonial, que al implantar sus códigos legales va a cambiar el marco legal existente, con un proceso de transculturación que produjo una nueva cultura legal, en la que el individuo cobra relevancia por encima de la comunidad. Los nuevos estados-nación, seculares en la mayor parte, se encargarán de aplicar la ley, con disposiciones que otorgan un rol al Estado previamente inexistente, en la creación y aplicación de la ley islámica, especialmente porque se codifica parte de ella en los códigos del estatuto personal.

Por otra parte, el derecho islámico, con la codificación de sus leyes, devino en un positivismo legal. Los nuevos códigos incluirán categorías desconocidas como derecho civil o mercantil, privado, etc. Con la introducción de modelos económicos y

\footnotetext{
${ }^{72}$ MELCHERT, Ch., The formation of the Sunni schools of law ninth-tenth centuries C.E. Universidad de Pensilvania. U.M.I dissertation services. Michigan. 1995. p.2. Además, el hecho de la no fijación de la doctrina en forma de códigos legales en el periodo pre-moderno "unido a la existencia de doctrinas discrepantes con un valor jurídico equivalente permite a los juristas adaptar la jurisprudencia a las necesidades de cada momento y lugar y proporcionar al sistema una flexibilidad, que poco corresponde con la rigidez con la que el derecho islámico ha sido representado por muchos que lo han estudiado". SERRANO, D., "Ley religiosa y Estados islámicos contemporáneos" en Ilu. Revista de Ciencias de las Religiones. Anejos. 2004, XI. p. 109.
} 
políticos distintos a los de las sociedades musulmanas, el fiqh quedó confinado al derecho de familia imbuido en un sistema híbrido, en el que resto de las leyes serían aplicadas por el Estado; algo que, además, tuvo un efecto negativo para la ley y jurisprudencia islámicas. En palabras de Hallaq "se engendrará una rigidez jurídica a través del entexting y una politización a través de su implantación". 73

El fiqh y su diversidad jurídica se convirtieron en una ley uniforme, pues el dinamismo que la ley tenía desapareció y fue herméticamente encerrada en el molde del entexting. Esto equivale a decir que se desposeyó al fiqh de su capacidad de adaptación a casos que demandaban un estudio de las circunstancias específicas, para volverse obsoleto en libros y codificaciones de casos pasados en materia del estatuto familiar. Y a su vez, todo aquello que no pertenecía a esta última área del estatuto familiar y que tradicionalmente era cubierto por los tribunales islámicos, pasaría a ser desarrollado por los nuevos códigos legales foráneos ${ }^{74}$.

Como bien indica Hallaq, una de las estrategias del colonialismo fue la producción de un considerable cuerpo linear de conocimiento que inventó dos realidades [...]: la narrativa académica de la historia legal islámica, narrativa que trajo a su vez el campo de "los estudios legales islámicos", la entidad socialmente construida que ahora denominamos "ley islámica". 75

El Orientalismo trajo consigo la concepción del Islam como un bloque estático con leyes inmutables, que produjo la deformación del rol de la jurisprudencia, que se convertía en un todo y se traducía como Charía. Con la empresa colonial se va a proceder a la codificación de libros de leyes en muchos países musulmanes, en los que se reflejaban aspectos de la tradición de los mismos.

La tendencia en el sunnismo será la utilización del taqlid, ${ }^{76}$ que supone la aceptación y práctica de las doctrinas por las escuelas y autoridades, imitándolas una y otra vez. De este modo, no ha lugar a la exégesis de los textos a través del ejercicio del juicio independiente. Con este sistema se despojaba de dinamismo a la ley, volviéndola totalmente rígida. Las fetuas y las doctrinas de las escuelas fueron compiladas en manuales legales con objeto de favorecer el taqlid, la compilación del fiqh se limitaba a comentar trabajos realizados dentro de cada escuela jurídica. ${ }^{77}$ El chiismo duodecimano

\footnotetext{
${ }^{73}$ HALLAQ, W B., Shari‘a, cit. p. 548. La palabra "entexting” que usa Hallaq no figura en el diccionario, pero podemos traducirla de manera aproximada por "codificación".

${ }_{74}$ Algunos casos pertenecientes al estatuto personal y que no tienen legislación previa siguen estando necesitados de fatwas (opiniones legales) que son realizadas por expertos legales, pero son los menos.

${ }^{75}$ Ibid. p. 10.

${ }^{76}$ Se puede traducir el término también como imitación ciega, aceptación que no se cuestiona, proviene de la palabra qallada que significa "poner algo en el cuello de otro". Ver JACKSON, S A., Islamic law and the state. The constitutional jurisprudence of Shihab al-Din al-Qarafi. AA.VV.(ed: B. WEISS. and R. PETERS). Studies in Islamic Law and Society, Volume 1. E.J.Brill. Leiden. 1996. p.79-80. También se entiende como imitación jurídico-doctrinal, el seguimiento por parte de un experto en leyes, un alfaquí o un ulema, de lo interpretado previamente por otro muytahid. En GÓMEZ, GARCÍA, L., cit. pp. 326327. Este término también es diferente al de ittiba', que significa seguimiento pero razonado.

${ }^{77}$ Algunas autores que argumentan el ascenso del taqlid arguyen que este se originó por la formación de las escuelas de jurisprudencia. El califato abasí se dividió en mini-Estados, lo que no favorecía el interés en la ley islámica; además, cada uno de estos Estados se adhería a una escuela jurídica a la que los jueces debían adaptarse también. A esto se unía el riesgo de que estudiosos de la ley incompetentes utilizaran el iytihad, dando lugar a malas interpretaciones, por lo que se pensaba que al restringir el iytihad se protegía la ley. Ver BILAL PHILIPS, A A. cit. pp.140-141.
} 
no dejó de aplicar el iytihad, sobre todo el de los imanes, por lo que nunca estuvieron a favor de la creencia del cierre de la puerta del iytihad.

El orden establecido que imponía la práctica del taqlid fue discutido, ya que en la época clásica se promovió en detrimento del iytihad, y en muchos casos no practicado por eruditos que creían que su obligación era practicar el iytihad. Por ejemplo, Ibn Taymiyya (1263-1328) fue uno de los grandes defensores de la práctica del iytihad, como también Muhammad Ibn Ali ash-Shawkani, Shah Waliullah Dihlawi, Jamal adDin Al-Afgani, Muhammad Ibn al-Wahhab, Ahmad ben Idris, Muhhamad ben Ali alSanusi, Muhammad Iqbal, Mohammad Abduh, Rachid Rida; estos últimos harán un llamamiento a la revitalización del mismo desde finales del S.XIX.

En contra de la opinión generalizada, diversos estudios demuestran que efectivamente el iytihad nunca dejó de ejercerse, por ejemplo en el caso de Ibn Taymiyya la puerta del iytihad nunca se cerró ni en la teoría ni en la práctica. Taymiyya fue considerado como un muytahid mutlaq, quien, sin embargo, tampoco desterró totalmente el taqlid, pues adoptaba también decisiones influenciadas por su escuela, la hanbalí (para estos últimos el iytihad es una obligación que debe prevalecer en todos los eruditos musulmanes). El uso del iytihad se refleja claramente en sus fetuas. ${ }^{78}$

Para demostrar que el iytihad se ejerció sin interrupción, el profesor Wallael Hallaq hizo un estudio examinando exhaustivamente los textos de los juristas desde el siglo noveno; la razón principal es que el iytihad era indispensable en la teoría legal, para que los juristas pudieran derivar juicios legales. Su investigación excelente y de indispensable lectura, muestra cuatro puntos clave: el primero, que los juristas capaces de realizar iytihad existieron siempre; segundo, que fue utilizado para desarrollar derecho positivo después de la formación de las escuelas; tercero, que hasta el 500 (A.H, Anno Hijrae o DH) no hubo mención de la frase insidad bal al-iytihad (cierre de la puerta del iytihad), o de cualquier expresión que aludiera a la misma; y cuarto y último, que la controversia en relación al cierre de la puerta del iytihad y la extinción de los muytahids impidió a los juristas alcanzar el consenso en relación a estos hechos. ${ }^{79}$. Autores como Muhammad Iqbal afirmaban que: "el cierre de la puerta del iytihad es meramente ficticio, que fue sugerido, en parte, por la cristalización del pensamiento jurídico en el islam, y en parte por la pereza intelectual que, sobre todo en el periodo de decadencia espiritual, convirtió en ídolos a los pensadores" ${ }^{\prime 80}$.

La filosofía del iytihad, aparte de ser un término técnico inserto en la metodología para el conocimiento más preciso de los textos y de su aplicación, también engloba filosofías como la del conocimiento y el sentido de comunidad, pues se la considera fard kifaya, esto es, una obligación para la convivencia, el desarrollo y la

\footnotetext{
${ }^{78}$ JOKISCH, B. "Ijtihad in Ibn Taymiyya's fatawa”, en AA.VV. (ed: R. GLEAVE and E. KERMELI), Islamic law theory and practice. I.B.Tauris. New York. 1997. pp. 119-137.

${ }^{79}$ HALLAQ, W B., "Was the gate of ijtihad closed? International Journal of Middle East Studies 16. New York. 1984. pp 3-41. Y HALLAQ, W B., "On the origins of the controversy about the existence of Mujtahids and the Gate of Ijtihad". Studia Islamica 63. Paris 1986. pp129-141. Ambos en HALLAQ, Wael B., Law and Legal Theory, cit. El primer artículo aborda las siguientes cuestiones: del iytihad en la teoría legal, cómo los grupos anti-iytihad quedaron excluidos del sunísmo, los muytahids en el siglo cuarto, el iytihad y la ley en el siglo quinto, el iytihad de autores como Juwayni, Gazele, Ibn Aquil, Suyuti, la expresión "el cierre de la puerta del iytihad", la controversia sobre la existencia de muytahids y el iytihad después del S.X.

${ }^{80}$ IQBAL, M., La reconstrucción, cit. p.165.
} 
búsqueda del bienestar de la comunidad. Este deber colectivo, además, no es objeto de control por ninguna institución política, quedando lejos de la manipulación del poder político, mecanismo que el Islam ya previó para evitar cualquier sistema de legitimación a través de la religión de cualquier mandatario o Estado.

El derecho es una visión de lo real y la tensión constante del fiqh ha sido, y es, la adaptación de los textos sagrados al contexto temporal e histórico en el que se pretende aplicar la normativa legal islámica. Cuando se impusieron los códigos legales occidentales las sociedades musulmanas no estaban preparadas para aceptar y vivir sin los códigos o normas, legislación islámica, que habían regulado históricamente su umma, les resultaba de difícil comprensión. De ahí la necesidad de conciliar la charía y a su vez las reivindicaciones sociales, para adaptar ambas a la situación histórica del momento, para propiciar una simbiosis que implica la existencia de ambas. No debemos olvidar el papel preponderante que han desempeñado el consenso (iyma') y la consulta (shura) en el Islam y en la historia de la teoría legal clásica.

El derecho islámico es la resulta producida entre la ley islámica, el fiqh y una sociedad imbuida en la modernidad ${ }^{81}$, con otros códigos legales occidentales. De la imbricación de este proceso depende la legitimación de la norma, sobre todo, para encontrar un punto común entre los partidarios de la interpretación literal de los textos divinos y los que sostienen una interpretación de la ley entre el dogma y el interés de la comunidad.

Los orientalistas han centrado gran parte del estudio del Islam en la ley y en lo difícil que es adaptarla a las sociedades actuales, pero el Islam es más una llamada religiosa y moral que un código jurídico. Obviar las nociones que no son sólo legales reduce su ámbito de aplicación, e induce a una comprensión a priori equivocada del Islam. Esto no sólo es una percepción errónea por parte de los orientalistas, sino que se convertirá y esto es lo importante, en un discurso reivindicativo de la identidad por parte de los islamistas, quienes minimizarán también toda la temática coránica para realzar la ley como elemento fundamental islámico y convertirla en el objetivo político prioritario. Lo que no se debe olvidar es que la meta de la ley islámica y su jurisprudencia es la epiqueya, es decir, la interpretación moderada y prudente de la ley, según las circunstancias de tiempo, lugar y persona ${ }^{82}$.

\footnotetext{
${ }^{81}$ Intentamos expresar con el término modernidad aquellas ideas que han transmitido las sociedades occidentales al mundo islámico y, en concreto, al derecho. Saint-Prot menciona que el término moderno no es sinónimo de progreso y tiene ese cariz de rendir culto a la época que es por naturaleza lo efímero, la moda. La modernidad que nació como ideología de los pensadores franceses prerrevolucionarios del S.XVIII, los de las llamadas lumieres. La ideología de la modernidad lleva esencialmente la marca del individualismo, que siempre ve al individuo y sus derechos y nunca a la sociedad. La modernidad pasa por alto la comunidad e idealiza al individuo, desprecia a la sociedad, aboga por la destrucción de los órdenes antiguos (naturales) y acaba por despojar de dimensión histórica al hombre. Frente al individuo abstracto y desarraigado de los ideólogos de la modernidad, tenemos al hombre concreto e histórico de la tradición religiosa. En SAINT-PROT, Ch., La tradición islámica, cit. p.13

${ }^{82}$ Se puede encontrar dicha descripción en, Diccionario de la lengua Española, cit. p.941.
} 


\section{BIBLIOGRAFÍA}

AKAR, S., But if you desire God and his Messenger. The concept of choice in sahih alBukhari. Studia Orientalia, Vol.102. Finnish Oriental Society. University of Helsinky. Helsinki. 2006.

AL-KHUDRAWI, D., Dictionary of islamic terms, Qamus al-lafoz al-islamiya. Arabicenglish, english-arabic. Al Yamana, Beirut 2010.

Al Mawardi. (trad: W H.Wahba). The ordinances of government. Al-Ahkam alSultaniyya w'al-Wilayat al-Diniyya.. Garnet Publishing. UK.2006.

ALI NADWI, S A., (Trad. Y ed: A. Salahi). Hadiz status \& Role. An introduction to the Prophet's tradition.. UK Islamic Academy. Unated Kingdom. 2005.

AMANAT, A. y GRIFFEL, F. (ed.), Sharía: Islamic law in the contemporary context. Standford University Press. California, 2007.

AN-NA'IM, A A, Islam and the secular state negotiating the future of shari 'a. Harvard University Press. Cambridge, Massachusetts and London, 2008.

AZAMI, M., "Hadiz: rules for acceptance and transmission" en The Place of Hadih in Islam. The Muslim Students Association of the United States and Canada. International Islamic Publishing house. Seminar on the 11 june of 1975. Arabia Saudi.

BALTA, P. (comp.), Islam, Civilización y sociedades. Siglo XXI de España editores. Segunda edición. Madrid. 2006.

BORRAS, A. y MERNISSI, S. (ed.), El Islam jurídico y Europa, derecho, religión y política. Icaria Editorial. Antrazyt. Barcelona, 1998.

BROWN, J A.C., "Did the Prophet say it or not? The literal, Historical, and Effective Truth of Hadiz in early sunnism". Journal of the American Oriental Society 129.2, 2009.

COULSON, N J., (Trad: M. Eugenia Eyras). Historia del Derecho Islámico. Biblioteca del Islam Contemporáneo, numero 10. Barcelona. 1998.

Diccionario de la lengua Española. Vigésimo segunda edición. Madid.2001. Tomo I.

DUPRET, B., (Trad: J. Miguel Marcén) La sharía. Orígenes, desarrollo y usos contemporáneos. Biblioteca del Islam Contemporáneo. Ediciones Bellaterra.. Barcelona. 2015.

DUTTON, Y., The origins of Islamic law. The Qur'an, the Muwatta and Madinan Amal. Curzon Press. Richmond, 1999.

El Noble Corán y su traducción comentario en lengua española. (Trad. y comentario de A G. Melara Navio). Complejo del Rey Fahd para la edición del Noble Corán en 
Medina Al Munawara. Bajo la supervisión del Ministerio de Asuntos Islámicos, Hadices, Propagación y Orientación del Reino de Arabia Saudí. Año 1417de la Hégira (1996).

Enciclopedia Jurídica, disponible en http://www.enciclopediajuridica.biz14.com/d/doctrina/doctrina.htm

ESMAEILI, H, "The nature and development of law in Islam and the rule of law challenge in the Middle East and the Muslim world". 26 Connecticut Journal of International Law 329-366 (2011).

ESPOSITO, JL., Oxford dictionary of Islam. Oxford University Press, 2003.

FATOOHI, L., Abrogation in the Qur'an and Islamic Law. A critical study of the concept of "Naskh" and its impact. Routledge. Nueva York. 2013.

GARAUDY, R., (Trad: C. Gardini). Los integrismos, el fundamentalismo en el mundo. Gedisa editorial.. Cuarta reimpresión en Barcelona 2001.

GÓMEZ GARCÍA, L., Diccionario de Islam e islamismo. Espasa Calpe, Madrid. 2009. HALLAQ, W B., An introduction to Islamic Law, Cambridge University Press, United Kingdom 2009.

HALLAQ, W B., Shari'a, theory practice transformations. Cambridge University Press. Cambridge. 2009.

HALLAQ W B., A history of Islamic legal theories. An introduction to sunni usul alfiqh. Cambridge University Press. United Kingdom, 1997.

HALLAQ, W B., Law and Legal theory in classical and Medieval Islam. VARIORUM. Aldershot, Hampshire. 1994.

HAMIDULLAH, M., "The first written constitution of the world". 1941 en https://archive.org/details/THEFIRSTWRITTENCONSTITUTIONOFTHEWORLD

HASHIM KAMALI, M., Principles of islamic jurisprudence. The Islamic texts society. Cambridge, edición 2003.

IBN ABDUL LATEEF AL MAHMOOD, A., A book on Islamic studies. Kitaab almutaalaah. Darussalam. Riyadh. 2010.

IBN KATHIR, (ed: S.Cook y trad: N. Eweiss) Moajiset el Nabi (the miracles of the Prophet). Dar al Manara. Egipto, 2002.

IBN KHALDUN, Al Muqaddimah. (Trad. y presentado por Franz Rosenthal con nueva introducción de Bruce, Lawrence B.), Princeton University Press. New Jersey. Edición 2005.

IQBAL, M., La reconstrucción del pensamiento religioso en el Islam. Trotta, Madrid. 2002. 
JABIR AL ALWANI, T, Source methodology in Islamic jurisprudence (Usul al-Fiqh al Islami). International Institute of Islamic thought. Virginia, USA. 1415/1994.

KNUT, V., Between God and the Sultan. A history of Islamic law. Hurst and Company. London. 2005.

LAROUI, A., (Trad: C. Ruiz Bravo). Ediciones de península El Islam árabe y sus problemas. . Barcelona. Edición 2001.

MAKDISI, G., Religion, Law and Learning in Classical Islam, Ashgate, VARIOURUM, London, 1986.

MAKDISI, G., "Ash'ari and the Ash'arites in Islamic Religious History I". Studia Islamica.N.17. (1962).pp.37-80. en http://www.academia.edu/7491514/6_Ash\%CA\%BFar\%C4\%AB_and_the_Asharites_i n_Islamic_Religious_History-I

MANDIROLA BRIEUX, P, Introducción al derecho Islámico. Marcial Pons ediciones jurídicas y sociales. Madrid. 1998.

MASUD K., MESSICK M., B y POWERS S. D (ed.) Islamic Legal interpretation. Muftis and their fatwas. Center for Middle Eastern studies, Harvard Studies in Islamic law. Harvard University Press. London. 1996.

MELCHERT, Ch., The formation of the Sunni schools of law ninth-tenth centuries C.E. Universidad de Pensilvania. U.M.I dissertation services. Michigan. 1995.

PETERS, R, Crime and Punishment in Islamic Law. Theory and Practice from the sixteenth to the twenty-first century. Cambridge University Press. Cambrige, 2005.

PHILIPS, A A B., The evolution of fiqh. Islamic Law \& the Madh-habs. International Islamic Publishing House. New revised edition 3. Riyadh. 2006.

RICHARD, Y., (Trad: J. Vivanco) El Islam Shií. Biblioteca del Islam Contemporáneo. Ediciones Bellaterra.. Barcelona. 1996.

ROY, O., (Trad: J. Vivanco) Genealogia del islamismo.. Biblioteca del Islam contemporáneo 5. Ediciones Bellaterra. Barcelona. 1996.

SCHACHT, J, An introduction to Islamic law. Oxford University Press. London 1964.

SEGURA I MAS, A., Aproximación al mundo islámico. Editorial UOC. Barcelona. 2002 .

SEMAAN, Khalil, Ash-Shafi'is Risalah: Basic Ideas. Arthur Jeffery Memorial Monographs No.1. Publicado por Muhammad Ashraf Kashmiri Bazar, Ashraf Press, Lahore. Pakistán. 1961. 
SERRANO, D., "Ley religiosa y Estados islámicos contemporáneos" en Ilu. Revista de Ciencias de las Religiones. Anejos. 2004, XI.

TAQUI-UD-DIN AL-HILALI, M., y MUHSIN KHAN, M., The Noble Qur'an. Darussalam. Arabia Saudí, Riyadh. 2002.

ZAMAN, I., "The science of Rijal as a method in the study of hadiths" Journal of Islamic Studies $\quad 5: 1$ pp.1-34 en https://asimiqbal2nd.files.wordpress.com/2009/06/thescienceofrijal.pdf. Y "The evolution of a hadith: transmission, growth and the science of Rijal in a hadiz of SA“AD B. ABI WAQQAS" en file://C:/Users/alg/Downloads/Zaman_Iftikhar_The\%20Evolution_ofa\%20_Hadith.pdf

Conferencia impartida en la Universidad Americana de Beirut del Profesor Abdullahi Ahmed An-Na‘im el 15/12/2009.

Entrevista personal realizada al Jeque Sami Jadra, religioso perteneciente al partido político y resistencia Libanesa Hezbolá. Beirut. Líbano, el 20/6/2013.

Entrevista personal realizada a Omar Bakri, fundador del movimiento islamista alMuhayirun (los emigrados) y al-Gurab (Los extranjeros), entrevistado en Trípoli y Beirut, Líbano. 28/03/2007, 21/3/2009 y en 2010.

Entrevista personal realizada al Jeque Afif Naboulsi, eminente jeque chí́ del sur del Líbano ligado a Hezbolá. Entrevista realizada en Saida, Líbano, en septiembre de 2010. 